Chapter 7

\title{
Programmed Cell Death as a Response to High Light, UV and Drought Stress in Plants
}

\author{
Weronika Wituszyńska and Stanisław Karpiński \\ Additional information is available at the end of the chapter \\ http://dx.doi.org/10.5772/53127
}

\section{Introduction}

Because of their sessile nature, plants are unable to avoid fluctuating environment conditions like high light, ultraviolet radiation, drought, salt stress, heat, cold or flooding. Upon certain threshold of these changes, plant cells can no longer maintain proper metabolic processes and programmed cell death (PCD) is induced.

PCD is an essential cell suicide process in animals, yeast and plants. In multicellular organisms, it plays an important role in the cell homeostasis maintenance, tissue specialization, removing of damaged or infected cells and acclimatory response. In contrast to necrotic death, which proceeds via swelling, lysis and leakage of cell content, PCD is a highly regulated and organized process. This controlled disassembly of cell involves the condensation, shrinkage and fragmentation of both cytoplasm and nucleus and DNA laddering. Furthermore, while PCD can occur during development and is regulated by complex mechanisms, necrosis does not require the activity of proteases nor nucleases and is not associated with signal transduction pathways [1].

There are two main categories of PCD in plants: developmentally- and environmentally-induced PCD. The first one is a genetically encoded process which plays a crucial role in the development of some tissues and organs. It is involved in tracheary elements formulation during xylem differentiation. Tracheary elements are long cells that transport water and mineral salts, and serve as a structural support in vascular plants. Their formation occurs after secondary wall synthesis and begins with a collapse of the central vacuole and release of lytic enzymes, followed by degradation of cellular content [2]. Another example of developmentally-induced PCD is a formation of unisexual flowers in monoecious species (e.g. maize), bearing generative organs of both sexes on the same plant. Sex determination in these species involves the developmental arrest of one of the organ primordia - either the 
female or male within a bisexual floral meristem [3]. The production of complex leaf shapes also frequently employs PCD. Such remodeling of leaf blades occurs in Monstera obliqua, Monstera deliciosa or lace plant [4]. These species tend to induce death pathway in some patches of cells and thus form distinctive perforations within the leaf [5]. PCD is also engaged in such processes as dying of aleurone cells in seeds of monocots, root cap shedding or anther dehiscence. Senescence, which is the final stage of vegetative and generative development, preceding plant organs death, also involves PCD. In deciduous trees, senescence is exhibited in the changes of leaves color developing during autumn. It enables the active turnover of cellular material and its use in other organs. For example, nutrients, such as nitrogen, recycled from leaves are used for the synthesis of proteins that will be stored in stems and will support growth in the following vegetative season. Moreover, PCD during senescence helps to block spreading of diseases to still vital parts of the plant [6].

Developmental PCD is induced by internal factors and occurs at defined time and in particular plant tissue. On the contrary, environmentally-induced PCD is triggered by different stimuli ranging from pathogen infection to environmental factors [7]. During infection of plant leaves by pathogens, a specific gene-for-gene (avr-R) interaction triggers defense responses. Upon such plant-microbe interaction, cell death takes a form of so-called hypersensitive response (HR) and includes a burst of reactive oxygen species (ROS). HR leads to the formation of a lesion which is clearly delimited from surrounding healthy cells and thus prevents the spread of pathogen throughout the plant tissue. Certain mutations in many plant species have been demonstrated to cause spontaneous, HR-resembling lesions, which suggests that this type of cell death is under a genetic control. Such lesion mimic mutants are divided into two groups: related to the initiation of PCD (inappropriate induction of PCD and formation of localized lesion spots) or propagation (inability to stop PCD once it has been initiated). Both these groups of mutants are currently widely investigated since they can provide insight into the general mechanism of PCD in plants [8-12]. The existence of these two classes suggests that genetically distinct processes underlie the lesion formation: the initiation of cell death and its spread to surrounding cells as well as the existence of communication signals between dying and healthy cells in determining the lesion size.

In natural habitats, plants are constantly exposed to a variety of environmental stresses that can lead to the disturbance in cellular homeostasis and consequently limit crop yield. Programmed cell death is a fundamental cellular process associated with the defense responses to abiotic stimuli such as excessive irradiation, ozone, ultraviolet radiation, heat, cold, drought or flooding. One of the example factor triggering PCD is hypoxia, a condition in which plant is deprived of oxygen supply. In response to waterlogging and lower $\mathrm{O}_{2}$ concentration in the ground, cortex of the root can form aerating tissue called aerenchyma [13]. The internal air spaces are generated through PCD and facilitate gas diffusion from aerial organs to waterlogged roots [14]. Although it is unfavorable for biomass production, the selective death of cells and tissues under abiotic stresses eventually provides survival advantages for the whole organism. At the organismal level, PCD helps to maintain tissue and organ homeostasis, enables developmental adaptation and nutrient resorption from dying cells thus increases the probability of survival. It also leads to the signals transduction from 
cells undergoing PCD to healthy, not-affected cells and triggers stress tolerance and acclimation to adverse conditions $[6,15]$.

\section{Hallmarks and the regulation of programmed cell death}

While the cascade of events and molecules regulating PCD have been already well described in animal cells, mechanisms underlying plant PCD remain still inexplicable. Therefore, numerous studies in plants rely on the comparison of PCD mechanisms to animals. Apoptosis (wellstudied form of animal PCD) features in cell shrinkage, chromatin condensation, cleavage of DNA (called DNA laddering) and nuclear fragmentation. The mechanism of PCD depends on a family of cysteine proteases called caspases that cleave their target proteins after aspartic acid residues. Caspases are synthesized in the cell as inactive precursors (procaspases). Once activated, caspases cleave and activate other procaspases which results in a self-amplifying cascade. They can also cleave other proteins such as nuclear lamins or proteins that hold DNAdegrading enzymes in inactive form, releasing DNases to cut DNA. The destructive protease cascade is irreversible, therefore caspase activity needs to be tightly controlled. Procaspase activation is induced by the release of electron carrier protein - cytochrome c from mitochondria to the cytosol. The family of Bcl-2 proteins regulates the activation of programmed cell death. Some members of this family (e.g. Bcl-2) block the release of cytochrome c, inhibiting apoptosis. Others (e.g. Bax and Bak) act as PCD inducers, promoting cytochrome c leakage. IAP (inhibitor of apoptosis) proteins are another family involved in apoptosis regulation as they bind to some procaspases, preventing their activation or to caspases, inhibiting their activity. Proteins that block IAPs are released together with cytochrome $\mathrm{c}$ which increases the efficiency of cell death process [16].

Many hallmarks of plant PCD seem to be similar to animals such as cytoplasm shrinkage, chromatin condensation and DNA cleavage, mitochondrial swelling, disruption of organelles and plasma membrane collapse [17]. The major difference in executing PCD between animals and plants lies in the process of removing the cell content after its death. While in animal cells, removal action is undertaken by other cells to avoid the activation of inflammatory response, in plants there is a leakage of the cell content into the apoplast and remains are not engulfed by surrounding cells [10]. Moreover, plants exhibit some distinctive features of PCD that result from the presence of chloroplasts and the significance of vacuoles $[18,19]$. Plant vacuoles represent important storage organelles that are the repository of hydrolytic enzymes such as proteases, lipases and nucleases. Vacuoles are therefore postulated to play a role in the turnover of organelles and cytoplasm during autophagy as a part of clean-up system for dying cells. The component of this system is a caspase-like protease the vacuolar processing enzyme (VPE) which plays a crucial role in such PCD pathways as senescence, lateral root formation and hypersensitive response. Upon receiving pro-apoptotic signals, VPE activates hydrolases that execute the degradation of vacuolar membrane resulting in the release of hydrolytic enzymes and subsequent degradation of cell content [19]. 
Chloroplasts are strongly suggested to be key players during cell death responses as they constitute an important source of defense signaling molecules such as ROS, reactive nitrogen species (RNS) and defense hormones like salicylic acid (SA) and jasmonic acid (JA). The oxidative burst is one of the earliest and most common plant response to abiotic and biotic stimuli [20]. The application of chloroplast-targeted, ROS-generating herbicides such as methyl viologen (paraquat) induces cell death with the typical apoptotic traits [21].

Some of key proteins controlling animal cell death such as the Bcl-2 family and caspases have been proven to be not conserved in plants. It suggests that plants have developed some unique mechanisms of PCD [15]. Although orthologs of caspases have not been found in plants based on the sequence similarity, several studies using caspase-specific peptide inhibitors suggested the presence of caspase-like proteases (metacaspases) [22]. These caspase inhibitors have been demonstrated to prevent chemically-, UV- or HR-induced PCD [23-25] indicating that caspase-like proteins are indeed involved in the regulation of PCD in plants. Metacaspases (MC) differ from animal caspases in their substrate specificity as they cleave proteins after arginine or a lysine residues. Nine predicted metacaspase-encoding genes have been found in Arabidopsis thaliana and divided into two classes, depending on the presence (type I) or absence (type II) of the N-terminal zinc-finger domain that has the homology to the LESION SIMULATING DISEASE 1 (LSD1) protein (see later) [26,27]. This domain is known to participate in protein-protein interactions and could indicate that oligomerization is important for MCs type I activation. The catalytic activities of AtMC4, AtMC5 and AtMC8 have been found to be $\mathrm{Ca}^{2+}$-dependent while AtMC9 is active under mildly acidic conditions. Thus, alterations in cellular $\mathrm{Ca}^{2+}$ concentration and $\mathrm{pH}$, that are common during various stresses, may help to control MCs activation. The sequence of AtMC4 has also revealed potential self-cleavage sites that may facilitate additional regulation of protease activity to achieve sensitive control of PCD [28]. Additionally, metacaspase ATMC4 (AtMCP2) has been proven to play a positive regulatory role in biotic and abiotic stress-induced PCD [29]. AtMC1 and AtMC2, belonging to type I metacaspases, have opposite roles in the cell death control. There is a genetic evidence that AtMC2 acts as a negative regulator of AtMC1-induced PCD. Therefore, it is hypothesized that proteins belonging to MC family execute either anti- or pro-apoptotic functions and compete with each other in making the cell lifedeath decisions [30].

Although no orthologues of Bcl-2 family genes (Bcl-2 or Bax) have been found in plants, there are some studies demonstrating that the expression of these genes in plants can regulate programmed cell death pathway [31,32]. Transgenic plants overexpressing animal antiapoptosis genes such as $B c l-2$ have been proven to exhibit enhanced tolerance to both biotic and abiotic stress conditions [33,34]. Moreover, the homologue for animal Bax Inhibitor (BI) has been identified in Arabidopsis [35] and proven to inhibit cell death in plants expressing mammalian Bax [36]. Arabidopsis BI-1 (AtBI-1) has been reported to localize in the endoplasmic reticulum (ER) and to contain predicted transmembrane $\alpha$-helices in the sequence, that are conserved in two other AtBI-1-related proteins: BI-2 and BI-3. These proteins are hypothesized to function in a similar fashion to the Bcl-2 family - as regulators of pro-death or survival pathways [10]. In plants, mRNA level of AtBI-1 increases during leaf senescence 
and under different abiotic stresses. The loss of function in AtBI1 results in the mutant hypersensitivity to environmental stimuli, whereas its overexpression in retarded PCD [37].

Numerous signals are constantly integrated by the cell to decide whether to enter or not the cell death pathway. Different plant hormones are involved in the regulation of cell death under unfavorable conditions. One of the most important is SA which is intensively produced in cells after pathogen infection or various abiotic stresses [38]. Many lesion mimic mutants have constitutively elevated levels of SA [39]. At high concentrations, SA functions as a cell death inducer in cooperation with other signals. It can be also transported beyond the site of synthesis, acting as a signaling molecule and mediating systemic acquired resistance (SAR) a whole-plant resistance response that prepares plant for another infection [40]. The existence of SA-dependent generation of ROS and the feedback control of SA synthesis by ROS have been also demonstrated [41]. SA and ROS have been proposed to work in a potentiation feedback loop which acts to amplify signals leading to cell death. Another cell death signaling molecule - nitric oxide (NO) has been also demonstrated to regulate key steps in SA biosynthesis during pathogen infection [42]. Additionally, NO has been proven to cooperate with ROS and SA in inducing cell death [43]. Other phytohormones regulating cell death under stress conditions are JA, gibberellic acid (GA), abscisic acid (ABA) and ethylene (ET). The latter is involved in the regulation of PCD during different developmental processes and responses to environmental stimuli. ET has been proven to participate in the formation of aerenchyma in roots under hypoxia [14]. Antisense inactivation of the ET biosynthetic enzyme - ACC oxidase delays leaf senescence and cell death in tomato [44]. Ethylene is also required for the continuation of ROS accumulation - external supply of ET during cell death increases ROS production and causes accelerated spreading of cell death [45]. JA is a plant signaling molecule best known for its role in the wound response but it is also produced during wide range of biotic and abiotic stresses. It is involved in the inhibition of ROS- and ET-dependent lesion propagation [46]. JA derivatives such as methyl jasmonate (MeJA) are also engaged in the regulation of plant immune responses [47]. Upon exposure to stress, MeJA is produced and causes the activation of PCD through the induction of ROS generation, alterations in mitochondrial dynamics and photosynthetic collapse [48]. Another phytohormone - GA has been proven to promote cell death in cooperation with ROS, whereas ABA delays GA-induced PCD. Such counteracting role of these hormones relates to their influence on the ROS-scavenging enzymes expression [49]. ABA has been also shown to delay ET- and GA-induced cell death in rice epidermal cells [50]. All these interactions between phytohormones and ROS indicate the complexity of PCD regulation. Overmyer and colleagues [39] suggested the following series of events during oxidative stress-triggered PCD. At the site of lesion initiation, the action of ROS is amplified. Increased ROS accumulation together with SA induces the cell death. During the initial process, JA signaling is hindered by SA and ET. Meanwhile, the burst of ET from the initial site disperses to surrounding cells, amplifies ROS production that promotes the lesion spread. This is the signal to induce competitive reactions to PCD. Cell death results in the production of JA which acts as a negative regulator of the oxidative cell death cycle. JA, through the suppression of SA biosynthesis/signaling and the attenuation of ET sensitivity, inhibits the lesion propagation. 
During early events of hypersensitive response, ion fluxes are induced. $\mathrm{Ca}^{2+}$ influx caused by external hydrogen peroxide application has been demonstrated to be sufficient in triggering HR in soybean cells [51]. Moreover, several cell death signaling proteins in plants exhibit a function associated with lipids. Two Arabidopsis mutants, eds1 and pad4 have been proven to be defective in HR signaling. EDS1 (ENHANCED DISEASE SUSCEPTIBILITY 1) and PAD4 (PHYTOALEXIN DEFICIENT 4) genes encode proteins with triacylglycerol lipase function $[52,53]$ which provides a genetic evidence that phospholipid signaling is involved in the induction of PCD. The level of phosphatidic acid (PA), produced by the phospholipase D (PLD) increases during defense response [54]. One of PLD isoforms in Arabidopsis has been shown to impair ROS-mediated PCD in response to biotic and abiotic stimuli [55], indicating the role of PA as a negative signal of cell death propagation. It is also hypothesized that the perturbation in sphingosine transport may cause cell death in plants since the mutation in ACD11 gene encoding a sphingosine-transport protein, results in a lesion-mimic phenotype that is dependent on EDS1, PAD4, SA and light [56]. EDS1 and PAD4 are extensively studied regulators of PCD. They constitute a regulatory hub that transduces redox signals in response to biotic and abiotic stresses. Both EDS1 and PAD4 are also important activators of SA signaling and mediate antagonism between JA and ET pathways during defense responses [57]. Furthermore, they are responsible for the biotic and abiotic stress-induced PCD in the LESION SIMULATING DISEASE 1 (LSD1) mutant [58,59]. The $1 s d 1$ mutant fails to limit the spread of PCD under long photoperiod or after the infection with avirulent pathogens. It is one of the best characterized mutants in terms of programmed cell death. The $l s d 1$ mutant exhibits a runaway cell death (RCD) phenotype (Figure 1B) manifested in the inability to restrict the progression of cell death once it has been initiated $[9,11]$, which provides a genetic evidence for LSD1 as a PCD repressor.
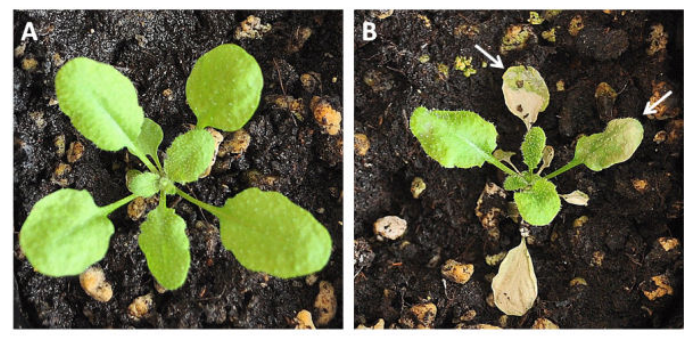

Figure 1. Runaway cell death (RCD) phenotype in the Isd1 mutant. 3-week-old Arabidopsis thaliana rosettes grown in long photoperiod (>11 h); A - wild type; B - Isd1 mutant. Arrows indicate leaves undergoing runaway cell death.

The $l s d 1 /$ cao double mutant which has reduced photosystem II (PSII) antenna size and thus reduced light absorption capacity due to the cao mutation in chloroplast signal recognition particle (cpSRP43), exhibits higher non-photochemical quenching (see later) and inhibited RCD after excess light exposure in comparison to the $l s d 1$ mutant. Therefore, the RCD in the lsd1 mutant has been linked to the amount of light energy absorbed in excess by the PSII light harvesting complex [11]. It has been shown that ET and ROS production in the $l s d 1$ 
mutant plants is elevated after plastoquinone reduction. The RCD in the $l s d 1$ mutant plants has been also proven to be inhibited by the mutation in EIN2, which encodes an ethylene receptor. Additionally, the artificial impeding of foliar gas exchange in $l s d 1$ has been shown to induce RCD, while high $\mathrm{CO}_{2}$ level has prevented cell death in this mutant. Importantly, lsd1 phenotype depends on EDS1 and PAD4, since in double mutants eds1/lsd1 and pad4/lsd1 PCD is inhibited $[11,14,60]$. The formation of ROS by plasma-membrane-bound NADPH oxidase has been proposed to play a major role in RCD in the $l s d 1$ mutant during the shift from short to long photoperiod, since the inhibition of this enzyme diminishes the formation of lesions [61]. All these results suggest that LSD1 acts as a ROS rheostat and is necessary for acclimation to conditions that promote oxidative stress. While LSD1 has been proven to negatively regulate the cell death, a highly similar protein - LOL1 (LSD1 like 1) is suggested to be a positive PCD-regulator [62]. It has been proposed that LSD1 and LOL1 might function in an antagonistic fashion to regulate the cell death propagation. Both LSD1 and LOL1 are putative transcription factors (TF) or scaffold proteins since they possess zinc-finger domains responsible for DNA/protein binding. Such $\mathrm{Zn}$-finger motif of the $\mathrm{C} 2 \mathrm{C} 2$ class has been found in plants, algae and protozoa, but not in animals. Apart from LSD1 and LOL1, only five other Arabidopsis proteins contain one or more LSD1-like Zn-finger domains: LOL2, LOL6 and already mentioned metacaspases: AtMC1, AtMC2 and AtMC3 [12]. The second and third Zn-finger domains of LSD1 are responsible for interacting with metacaspase AtMC1, which is a positive regulator of PCD. The atmc1 mutation is able to suppress cell death in $l s d 1$. Furthermore, the interaction of LSD1 with AtbZIP10 transcription factor prevents its translocation to the nucleus. AtbZIP10 has been proven to be a positive mediator of RCD observed in the $l s d 1$ mutant [63].

\section{Reactive oxygen species in plants}

The signaling during PCD proceeds mainly through the regulation of reactive oxygen species $[60,64,65]$. ROS are produced continuously as by-products of various pathways localized in chloroplasts, mitochondria and peroxisomes. They can occur as free radicals: superoxide radical $\left(\mathrm{O}_{2}{ }^{\bullet-}\right)$, hydroxyl radical $\left({ }^{\bullet} \mathrm{OH}\right)$, perhydroxyl radical $\left(\mathrm{HO}_{2}{ }^{\circ}\right)$, alkoxy radical $\left(\mathrm{RO}{ }^{*}\right)$ or in non-radical forms: singlet oxygen $\left({ }^{1} \mathrm{O}_{2}\right)$ and hydrogen peroxide $\left(\mathrm{H}_{2} \mathrm{O}_{2}\right)$. Most abiotic stresses evoke the overproduction of ROS in plant tissues. Because of their high reactivity, ROS can cause damage of proteins, lipids, carbohydrates and nucleic acids, ultimately leading to cell death (Figure 2).

The single reduction of $\mathrm{O}_{2}$ results in the formation of $\mathrm{O}_{2}{ }^{-{ }^{-}}$. From $\mathrm{O}_{2}{ }^{--}$other more reactive ROS like ${ }^{\bullet} \mathrm{OH}$ or $\mathrm{HO}_{2}{ }^{\bullet}$ can be formed. The Haber-Weiss reaction generates hydroxyl radical from hydrogen peroxide and superoxide. In this reaction $\mathrm{O}_{2}{ }^{--}$donates an electron to $\mathrm{Fe}^{3+}$, reducing ferric ion to ferrous:

$$
\mathrm{Fe}^{3+}+\mathrm{O}_{2}^{\cdot-} \rightarrow \mathrm{Fe}^{2+}+\mathrm{O}_{2}
$$


The second step of $\cdot \mathrm{OH}$ formation is the Fenton reaction in which reduced form of iron $\left(\mathrm{Fe}^{2+}\right)$ transfers electrons to $\mathrm{H}_{2} \mathrm{O}_{2}$ :

$$
\mathrm{Fe}^{2+}+\mathrm{H}_{2} \mathrm{O}_{2} \rightarrow \mathrm{Fe}^{3+}+\mathrm{OH}^{-}+\cdot \mathrm{OH}
$$

$\mathrm{O}_{2}{ }^{--}$can be also protonated to form $\mathrm{HO}_{2}{ }^{\bullet}$. Furthermore, $\mathrm{O}_{2}{ }^{--}$can react with another free radical species as $\mathrm{NO}^{\bullet}$ to generate peroxynitrite $\left(\mathrm{OONO}^{-}\right)$[66]. Another form of ROS - singlet oxygen is the first excited electron state of $\mathrm{O}_{2}$ that originates when an electron is elevated to a higher energy orbital (Figure 3).

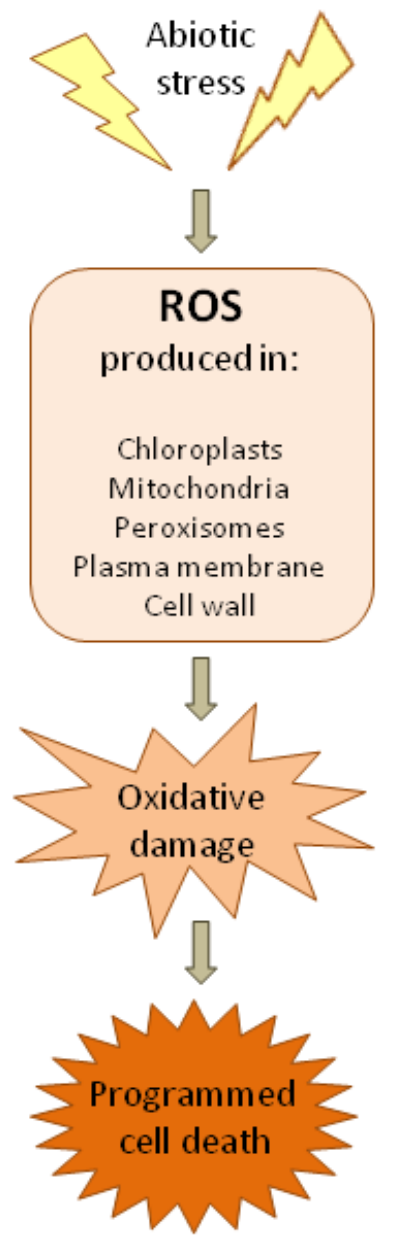

Figure 2. ROS production and programmed cell death induced by abiotic stress (according to Gill and Tuteja, 2010) [66]. 


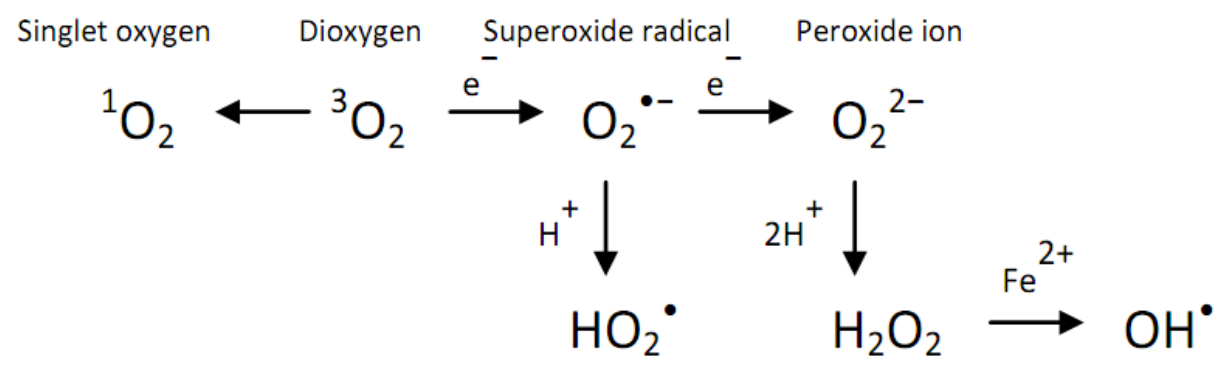

Perhydroxyl radical Hydrogen peroxide Hydroxyl radical

Figure 3. Formation of different ROS (according to Gill and Tuteja, 2010) [66].

Very reactive ${ }^{1} \mathrm{O}_{2}$ can be formed by the reaction of $\mathrm{O}_{2}$ with photo-excited chlorophyll. Inadequate dissipation of excess energy during photosynthesis can lead to the generation of chlorophyll triplet state. The $\mathrm{Chl}$ triplet state can react with ${ }^{3} \mathrm{O}_{2}$ to yield ${ }^{1} \mathrm{O}_{2}$ [67]. The formation of ${ }^{1} \mathrm{O}_{2}$ has extremely damaging effect on PSI and PSII and other components of photosynthetic machinery. The ${ }^{1} \mathrm{O}_{2}$ lifetime has been measured to be approximately $3 \mu$ s [68]. During this time, some part of ${ }^{1} \mathrm{O}_{2}$ fraction is able to diffuse over several hundred $\mathrm{nm}$, reacting with proteins, pigments, nucleic acids and lipids [69]. In Arabidopsis mutants favoring ${ }^{1} \mathrm{O}_{2}$ production, photooxidative stress has been demonstrated to cause dramatic increase in lipid peroxidation (LPO) that precedes cell death [70]. Plant chloroplasts avoid the accumulation of ${ }^{1} \mathrm{O}_{2}$ by employing $\beta$-carotene, tocopherol and plastoquinone to remove it. If the elimination is not sufficient, ${ }^{1} \mathrm{O}_{2}$ can lead to the upregulation of genes involved in defense responses against photooxdative stress [69]. These genes have proven to be different from those induced by $\mathrm{O}_{2}{ }^{--}$and $\mathrm{H}_{2} \mathrm{O}_{2}$ and it has been suggested that ${ }^{1} \mathrm{O}_{2}$ acts as a signal molecule that activates several stress-responsive pathways [71]. The reaction of superoxide radical reduction produces hydrogen peroxide. $\mathrm{H}_{2} \mathrm{O}_{2}$ is moderately reactive but has relatively long lifetime (1ms) in comparison to other ROS. $\mathrm{H}_{2} \mathrm{O}_{2}$ has been shown to be required in a broad range of physiological processes such as stomata movements [72], cell cycle [73] as well as growth and development [74]. It plays a dual role. At low, physiological concentration, $\mathrm{H}_{2} \mathrm{O}_{2}$ acts as a signal molecule involved in defense and acclimatory responses to various biotic and abiotic stimuli. At high concentrations, it reacts with cell constituents, e.g. inactivates enzymes by oxidizing their thiol groups and triggers PCD [75]. The highly reactive ROS - hydroxyl radical, produced in Haber-Weiss reaction can potentially react with many organic compounds including DNA, proteins and lipids. Due to the absence of enzymatic mechanism for ${ }^{\bullet} \mathrm{OH}$ elimination, its excess production leads to cell death [76].

It has been estimated that $1-2 \%$ of $\mathrm{O}_{2}$ consumed by plants is sidetracked for ROS production in different subcellular compartments [66]. Organelles such as chloroplasts, mitochondria or peroxisomes are major sources of ROS in plant cells since they exhibit an intense rate of electron flow and highly oxidizing metabolic activity. In chloroplasts, PSI and PSII are major sites where the singlet oxygen and superoxide radicals are generated. Under nonstress conditions, the electron from excited photosystem is transferred to $\mathrm{NADP}^{+}$, reducing it 
to NADPH. However, under various abiotic stresses, the electron transport chain (ETC) tends to be overloaded and a part of the electron flow is diverted from ferredoxin to $\mathrm{O}_{2}$, reducing it to $\mathrm{O}_{2}{ }^{--}$. The photoreduction of $\mathrm{O}_{2}$ at PSI proceeds via Mehler reaction and produces $\mathrm{O}_{2}{ }^{--}$, which is disproportionated to $\mathrm{H}_{2} \mathrm{O}_{2}$ and $\mathrm{O}_{2}$ with the use of superoxide dismutase. $\mathrm{H}_{2} \mathrm{O}_{2}$ is rapidly detoxified to $\mathrm{H}_{2} \mathrm{O}$ by the ascorbate peroxidase pathway (Figure 4A). Because of the electron flow from water in PSII to water in PSI that occurs in this process, it has been termed the water-water cycle [77]. This cycle does not only scavenge $\mathrm{O}_{2}{ }^{--}$and $\mathrm{H}_{2} \mathrm{O}_{2}$, but also generates a $\mathrm{pH}$ gradient across thylakoid membranes which enhances non-radiative dissipation of light energy by non-photochemical quenching (see later). Therefore, the water-water cycle is considered to function as a dissipatory mechanism of the excess energy $[77,78]$.

$\mathrm{H}_{2} \mathrm{O}_{2}$ is also produced during a process that proceeds concurrently to the photosynthesis photorespiration. During photosynthetic carbon assimilation, ribulose-1,5-bisphosphate carboxylase/oxygenase enzyme (Rubisco) uses $\mathrm{CO}_{2}$ to carboxylate ribulose-1,5-bisphosphate (RuBP). $\mathrm{CO}_{2}$ uptake results in the formation of two molecules of 3-phosphoglycerate (3PGA) that are utilized for biosynthetic reactions and the recycling of the RuBP acceptor molecule. However, Rubisco can also use $\mathrm{O}_{2}$ to oxygenate RuBP, forming one molecule of 3PGA and one molecule of 2-phosphoglycolate (2-PG). The latter cannot be used for biosynthetic reactions and is considered as an inhibitor of the chloroplast function. Photorespiration functions to convert 2-PG back to 3-PGA and thus to recover carbon. It constitutes a series of reactions taking place in chloroplasts, peroxisomes, and mitochondria. 2-PG is dephosphorylated to glycolate in the chloroplast and transported to the peroxisome where it is oxidized to glyoxylate. $\mathrm{O}_{2}$ is the electron donor in this reaction, which results in $\mathrm{H}_{2} \mathrm{O}_{2}$ generation. Glyoxylate is transaminated to glycine which is transported to the mitochondrion, where two molecules of glycine are converted to serine and the remaining carbon and nitrogen are released as $\mathrm{CO}_{2}$ and $\mathrm{NH}_{3}$, respectively. The amine group is used to form a new glycine from glyoxylate and the resulting hydroxypyruvate is reduced to glycerate. Finally, glycerate is phosphorylated in the chloroplast to form 3-PGA, which can be fed back to the Calvin cycle $[79,80]$.

The production of ROS is also an unavoidable consequence of the aerobic respiration. It occurs under normal respiratory conditions but can be enhanced in response to biotic and abiotic stress. ROS produced in mitochondria are regarded to be essential in PCD regulation [81]. In mitochondria, $\mathrm{O}_{2}{ }^{--}$is mainly produced in complex I, ubiquinone and complex III of ETC [82]. This $\mathrm{O}_{2}{ }^{\cdot-}$ can be further converted into highly toxic ${ }^{\circ} \mathrm{OH}$ which may penetrate membranes and leave the mitochondrion [83]. Hydroxyl radical can also initiate the peroxidation of mitochondrial membrane polyunsaturated fatty acids (PUFA) that leads to the formation of cytotoxic lipid aldehydes, alkenals and hydroxyalkenals, such as malonyldialdehyde (MDA). Lipid peroxidation products may cause cellular damage by reacting with other lipids, proteins and nucleic acids. The mitochondrial ETC produces significant amount of ROS but the mitochondrial enzyme - alternative oxidase (AOX) can prevent ROS overproduction [84]. Some studies, performed on tobacco plants, have demonstrated that the lack of AOX induces PCD while the AOX overexpression decreases the lesion size during HR $[85,86]$. 
Another source of ROS - peroxisomes are small, spherical organelles with an oxidative type of metabolism. There are two sites of $\mathrm{O}_{2}{ }^{--}$generation in peroxisomes: in the organelle matrix, where xanthine oxidase $(\mathrm{XOD})$ catalyzes the oxidation of xanthine and hypoxanthine to uric acid and in the membrane, by components of peroxisomal ETC. The main metabolic processes responsible for $\mathrm{H}_{2} \mathrm{O}_{2}$ generation in peroxisomes are photorespiratory glycolate oxidase reaction, fatty acid $\beta$-oxidation, enzymatic reaction of flavin oxidases and disproportionation of superoxide radicals [87].

ROS are also generated in the apoplast by NADPH oxidases residing in the plasma membrane and generating superoxide radicals. The extracellular $\mathrm{O}_{2}{ }^{\cdot-}$ is quickly mutated into $\mathrm{H}_{2} \mathrm{O}_{2}$ or converted to ${ }^{\circ} \mathrm{OH}$. The latter initiates a series of reactions that cause a plasma membrane damage, finally leading to cell death. Two Arabidopsis respiratory burst oxidase genes, $R B O H D$ and $R B O H F$, that encode NADPH oxidases have been proven to be responsible for ROS production during the HR. Enzymes such as cell wall peroxidases, germin-like oxalate oxidases and amine oxidases have been proposed as a source of hydrogen peroxide in the apoplast. The alkalization of apoplast upon elicitor recognition precedes the production of $\mathrm{H}_{2} \mathrm{O}_{2}$ by $\mathrm{pH}$-dependent cell wall peroxidases [88].

The peroxidation of lipids is considered as one of the most damaging processes occurring in the cell. The damage of membrane is often considered as a parameter determining the level of cell destruction under various stresses. Upon ROS overproduction, polyunsaturated precursors undergo lipid peroxidation, forming small hydrocarbon fragments such as ketones or aldehydes. LPO in both cellular and organellar membranes affects proper cellular functions and aggravates oxidative stress by the production of lipid-derived radicals [89]. This process often affects PUFA, since they contain multiple double bonds in between which lie methylene (-CH2-) groups with reactive hydrogens. Hydroxyl or perhydroxyl radicals combining with a hydrogen atom produce water and a fatty acid radical. The fatty acid radicals are unstable and react rapidly with molecular oxygen, creating a peroxyl-fatty acid radical $\left(\mathrm{ROO}^{\circ}\right)$. Once initiated, $\mathrm{ROO}^{*}$ can further propagate the peroxidation chain reaction by abstracting a hydrogen atom from PUFA side chains. The resulting lipid hydroperoxide easily decomposes into several reactive species including: lipid alkoxyl radicals, MDA, alkanes and lipid epoxides. Thus, LPO generates multiple peroxide molecules and results in the membrane fluidity decrease, its leakiness to substances that do not normally cross it, the damage of membrane proteins and ion channels. It has been found that such PUFAs as linoleic and linolenic acids are particularly susceptible to ROS attack [90]. Increased level of LPO has been demonstrated in many abiotic stress studies, for instance under salt stress in Oryza sativa [91].

Apart from lipid peroxidation, the accumulation of ROS leads to protein oxidation. Only few types of these covalent modifications are reversible, most of them are irreversible [92]. A widely used marker for protein oxidation is their carbonylation level. The oxidation of amino acids such as arginine, histidine, lysine, proline, threonine and tryptophan causes the formation of free carbonyl groups, that may inhibit or alter the protein activity and increase the susceptibility towards proteolytic attack [90]. Proteins with sulfur-containing amino acids and thiol groups are often the target for ROS. Cysteine and methionine are especially reac- 
tive with ${ }^{1} \mathrm{O}_{2}$ and $\bullet \mathrm{OH}$. Activated oxygen radical can abstract the hydrogen atom from cysteine residue to form a thiyl radical that cross-links to a second thiyl radical and leads to the formation of disulphide bridges. Oxygen can also be added onto the methionine residue to form a methionine sulphoxide. The best characterized response to the oxidation of peptide residues is the induction of proteases that break down the oxidized proteins [93].

DNA damage, triggered by ROS is particularly dangerous for the cell since it causes replication errors and genomic instability. From all $\mathrm{ROS}, \cdot \mathrm{OH}$ has the most damaging effect to DNA as it can modify all components of the nucleic acid molecule: purines, pyrimidines and the deoxyribose backbone [94]. The major types of DNA damage resulted from oxidative stress are the formation of dimers between adjacent pyrimidines, cross-links, base deletion, strand breaks and base modifications such as alkylation and oxidation. To counteract the DNA damage, plant cells evolved mechanisms for the DNA repair in both nucleus and mitochondria. These include the direct inversion of modifications or the replacement of the whole nucleotide [95].

To protect themselves against toxic oxygen intermediates, plant cells possess a vast antioxidant system. Stress-induced ROS accumulation is counteracted by both enzymatic and nonenzymatic antioxidants. Enzymatic ROS scavengers include superoxide dismutases (SOD), catalases (CAT), ascorbate peroxidases (APX), glutathione reductases (GR), monodehydroascorbate reductases (MDHAR), dehydroascorbate reductases (DHAR), glutathione peroxidases (GPX) and glutathione-S- transferases (GST). Low-molecular, non-enzymatic antioxidants include ascorbic acid (AsA), glutathione (GSH), proline, $\alpha$-tocopherol, carotenoids and flavonoids [73].

Metalloenzyme SOD is the most effective enzymatic antioxidant which is ubiquitous in all subcellular compartments. SODs remove $\mathrm{O}_{2}{ }^{--}$by catalyzing its dismutation (Figure 4A):

$$
\mathrm{O}_{2}^{\cdot-}+\mathrm{O}_{2}^{\cdot-}+2 \mathrm{H}^{+} \rightarrow 2 \mathrm{H}_{2} \mathrm{O}_{2}+\mathrm{O}_{2}
$$

This reaction eliminates $\mathrm{O}_{2}{ }^{\bullet-}$ and hence decreases the risk of ${ }^{\bullet} \mathrm{OH}$ formation. SODs are classified into three types, depending on their metal cofactor: copper/zinc ( $\mathrm{Cu} / \mathrm{Zn}-\mathrm{SOD})$, manganese (Mn-SOD) and iron (Fe-SOD). Different types of SODs are located in different cellular compartments [96]. Arabidopsis thaliana genome encodes three Fe-SOD (FSD1, FSD2 and FSD3), three Cu/Zn-SOD (CSD1, CSD2 and CSD3) and one Mn-SOD (MSD1) [97]. Mn-SOD has been found in mitochondria and peroxisomes of plant cells [98]. $\mathrm{Cu} / \mathrm{Zn}-\mathrm{SOD}$ isoenzymes have been found in the cytosol and in chloroplasts of higher plants. Fe-SODs are usually associated with chloroplasts [99]. The upregulation of SODs during biotic or abiotic stress-triggered oxidative stress has a critical role in the overcoming of adverse conditions and in the plant survival. Many reports indicate that the overexpression of different SODs leads to the generation of abiotic stress-tolerant plants, e.g. Mn-SOD overexpressing Arabidopsis has shown increased salt tolerance [100] and $\mathrm{Cu} / \mathrm{Zn}$-SOD overexpressing transgenic tobacco has demonstrated multiple stress tolerance [101]. Interestingly, FSD2 and FSD3 play also an essential role in the chloroplast development, protecting chloroplast nucleoids from ROS [102]. 
A

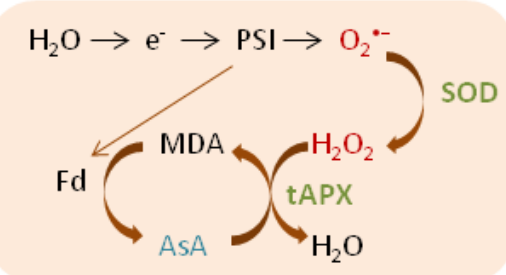

C

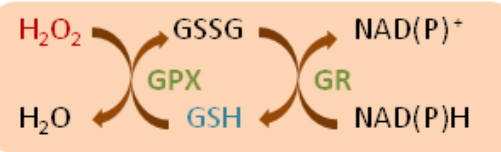

B
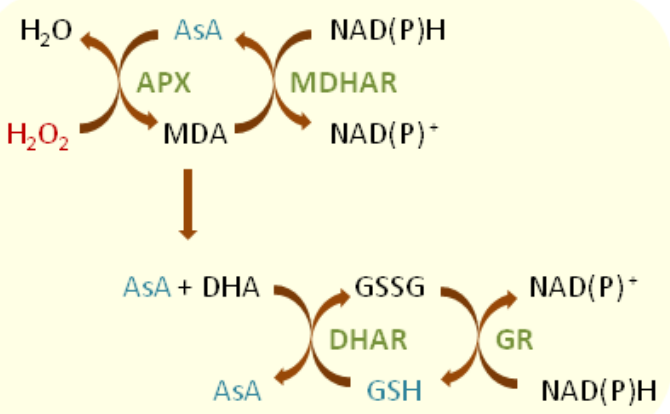

Figure 4. Different pathways for ROS scavenging in plants: A - the water-water cycle (Mehler reaction); B - the ascorbate-glutathione cycle; $\mathrm{C}$ - the glutathione peroxidase cycle. Superoxide dismutase (SOD) acts as the first line of defense converting $\mathrm{O}_{2}{ }^{-}$into $\mathrm{H}_{2} \mathrm{O}_{2}$, then ascorbate peroxidases (APX), glutathione peroxidases (GPX) and catalases (CAT not shown) eliminate $\mathrm{H}_{2} \mathrm{O}_{2}$. In contrast to CAT, both APX and GPX require ascorbate (AsA) or glutathione (GSH) regenerating cycles that use electrons from the photosynthesis $(A)$ or $N A D(P) H(B, C)$ as reducing power. ROS are indicated in red, ROS-scavenging enzymes in green and low-molecular antioxidants in blue. Abbreviations: DHA - dehydroascorbate; DHAR - DHA reductase; Fd - ferredoxin; GR - glutathione reductase; GSSG - oxidized glutathione; MDA - monodehydroascorbate; MDAR - MDA reductase; PSI - photosystem I; tAPX - thylakoid-bound APX (according to Mittler et al., 2004) [73].

Catalases are tetrameric enzymes containing heme with the potential to dismutate $\mathrm{H}_{2} \mathrm{O}_{2}$ into $\mathrm{H}_{2} \mathrm{O}$ and $\mathrm{O}_{2}$.

$$
2 \mathrm{H}_{2} \mathrm{O}_{2} \rightarrow 2 \mathrm{H}_{2} \mathrm{O}+\mathrm{O}_{2}
$$

CAT1 and CAT2 are localized in peroxisomes and cytosol, whereas CAT3 is targeted to mitochondria. Increased CAT activity has been reported in various abiotic stress studies in different species, e.g. under drought stress in wheat [103]. Moreover, a vast number of research indicate that CAT overexpression leads to the abiotic stress tolerance, e.g. wheat catalase expressed in transgenic rice has been demonstrated to improve the tolerance against low temperatures [104].

Another group of antioxidising enzymes - ascorbate peroxidases are involved in $\mathrm{H}_{2} \mathrm{O}_{2}$ scavenging in water-water and glutathione-ascorbate cycles and use ascorbic acid as the electron donor (Figure $4 \mathrm{~A}$ and $\mathrm{B}$ ). The reaction catalysed by APXs is the transfer of electrons from ascorbate to hydrogen peroxide, producing dehydroascorbate and water

$$
\mathrm{H}_{2} \mathrm{O}_{2}+\mathrm{C}_{6} \mathrm{H}_{8} \mathrm{O}_{6} \rightarrow 2 \mathrm{H}_{2} \mathrm{O}+\mathrm{C}_{6} \mathrm{H}_{6} \mathrm{O}_{6}
$$

In Arabidopsis thaliana, the presence of eight APX isoenzymes has been confirmed: soluble cytosolic (APX1, APX2, APX6), bounded to the microsome membrane (APX3, APX4, APX5), chloroplast stromal (sAPX) and thylakoid (tAPX). Higher expression levels of APXs have been demonstrated during different stress conditions and their overexpression has been pro- 
ven to enhance the plant resistance, e.g. tobacco plants with higher chloroplast APX expression are more tolerant to the salt stress and water deficit [101].

Glutathione reductases are oxidoreductases participating in the glutathione-ascorbate cycle (Figure 4B). They play an essential role in the defense against ROS by sustaining reduced status of glutathione (GSH), a tripeptide molecule involved in many regulatory and antioxidative processes in plants. They are localized predominantly in chloroplasts, but small amounts have been also found in mitochondria and cytosol [105]. GRs catalyze the NADPH-dependent reduction of the oxidized form of glutathione (GSSG) (Figure 4B and C) thus are important for maintaining the GSH pool. Increased GR activity has been demonstrated in various abiotic stress studies, e.g. in drought stressed rice seedlings [106]. Transgenic plants with lower GR activity have shown enhanced sensitivity to oxidative stress while these with higher GR have been proved to be abiotic stress tolerant. Elevated chloroplastic GR activity has been demonstrated to decrease chilling-induced photoinhibition in transgenic cotton [107].

Monodehydroascorbate reductase is an enzymatic component of the glutathione-ascorbate cycle (Figure 4B). MDHARs are present in chloroplasts, mitochondria, peroxisomes and cytosol, where they participate in $\mathrm{H}_{2} \mathrm{O}_{2}$ scavanging [108]. They exhibit high specificity for monodehydroasorbate as the electron acceptor and use NADH as the electron donor (Figure 4B):

$$
\mathrm{NADH}+\mathrm{C}_{6} \mathrm{H}_{7} \mathrm{O}_{6} \rightarrow \mathrm{NAD}^{+}+\mathrm{C}_{6} \mathrm{H}_{8} \mathrm{O}_{6}
$$

Overexpression of MDHAR in the transgenic tobacco has been demonstrated to increase the tolerance against ozone, salt and osmotic stress [109].

Dehydroascorbate reductases function in the regeneration of ascorbic acid from the oxidized form (Figure 4B) and therefore regulate cellular AsA redox state. DHAR overexpression has been demonstrated to enhance salt tolerance in Arabidopsis [110] as well as drought and ozone stress resistance in tobacco [111].

Glutathione S-transferases are a large and diverse group of enzymes with 54 members reported in Arabidopsis [112]. They catalyze the conjugation of electrophilic substrates with glutathione. Plant GSTs are known to participate in herbicides detoxification, hormone homeostasis maintenance, sequestration of anthocyanin and regulation of PCD in response to biotic and abiotic stimuli. They are mostly located in the cytoplasm but chloroplastic, nuclear and apoplastic isoforms have also been reported [113].

Glutathione peroxidases are another group of isoenzymes that use GSH to reduce $\mathrm{H}_{2} \mathrm{O}_{2}$, organic and lipid hydroperoxides (Figure 4C). A family of seven related proteins (AtGPX1AtGPX7) residing in cytosol, chloroplasts, mitochondria and endoplasmic reticulum has been identified in Arabidopsis [114]. Overexpression of GPX in transgenic tobacco has been demonstrated to confer tolerance towards chilling and salt stress [115].

Apart from enzymes participating in redox homeostasis maintenance, plants possess a vast number of non-enzymatic compounds acting as antioxidants. Ascorbic acid (vitamin C) is present in all plant tissues but especially high levels occur in photosynthetically active or- 
gans, meristems and some fruits. Mitochondria play a central role in the metabolism of AsA in plants. Ascorbic acid reacts with oxidants such as $\mathrm{O}_{2}{ }^{--}$and ${ }^{\bullet} \mathrm{OH}$, transfering a single electron and forming its own radical ion in the following reaction:

$$
\mathrm{RO} \cdot+\mathrm{C}_{6} \mathrm{H}_{7} \mathrm{O}_{6}^{-} \rightarrow \mathrm{ROH}+\mathrm{C}_{6} \mathrm{H}_{6} \mathrm{O}_{6} \cdot-
$$

The oxidized form of ascorbate - dehydroascorbate (DHA) is relatively unreactive and do not cause cellular damage. However, it has a short lifetime and needs to be regenerated back into AsA. Ascorbic acid antioxidative capacity provides a protection to membranes by direct scavenging ROS and by regenerating $\alpha$-tocopherol from tocopheroxyl radical. In chloroplasts, AsA acts also as a violaxantin de-epoxidase cofactor, sustaining dissipation of excess excitation energy [116].

Another powerful antioxidant - glutathione is a tripeptide ( $\gamma$-glu-cys-gly). In plant tissues it occurs in a reduced form (GSH) and plays a central role in several physiological processes, including detoxification of xenobiotics, signal transduction, conjugation of different metabolites, differentiation, senescence and cell death regulation [117]. By serving as an electron donor, GSH is converted into oxidized form - two glutathione molecules linked by a disulfide bond (glutathione disulfide, GSSG). Once oxidized, glutathione can be reduced by glutathione reductases that use NADPH as an electron donor (Figure 4C). The GSH/GSSG ratio is often used as a measure of cellular redox state. GSH is necessary to maintain reduced state of cell, counteracting inhibitory effects of ROS. It plays a key role in the antioxidative defense system by regenerating other antioxidants like AsA via the glutathione-ascorbate cycle (Figure 4B). GSH is particularly important in chloroplasts since it helps to protect the photosynthetic apparatus from oxidative damage [118].

Proline is considered as another important antioxidant and potential inhibitor of PCD. It has been well established that it acts as an osmoprotectant and protein-stabilizing agent. However, it has been also proven to be the $\mathrm{O}_{2}{ }^{-{ }^{-}}$and ${ }^{\circ} \mathrm{OH}$ scavenger and inhibitor of LPO [119]. Increased concentration of proline has been correlated with enhanced tolerance to various abiotic stresses, e.g. transgenic tobacco cells with silenced proline dehydrogenase, accumulating more proline than wild-type cells, have shown improved osmotolerance [120]. Overexpression of proline biosynthetic pathway genes has been also found to increase the drought stress tolerance in transgenic soybean [121].

Out of four tocopherol isomers $(\alpha, \beta, \gamma, \delta)$ found in plants, $\alpha$-tocopherol (vitamin E) has the highest antioxidative activity because of the presence of three methyl groups [122]. $\alpha$-tocopherol, a lipid soluble antioxidant molecule is considered as a potential scavenger of ROS and lipid radicals in membranes. It has been shown to prevent the chain propagation step in the lipid autooxidation reaction [123]. It has been demonstrated that oxidative stress activates the expression of tocopherols synthesis pathway genes. Higher tocopherol level has also been reported during water stress [124].

Another group of plant compounds with antioxidant abilities are lipid soluble carotenoids. They play various functions in the plant metabolism such as absorption of light at wave- 
length between 400 and $550 \mathrm{~nm}$ (light-harvesting role), assembly and stabilization of light harvesting complex proteins (structural role), and protection of the photosynthetic apparatus from free radicals (antioxidant role) [66].

Apart from the antioxidant function, flavonoids are responsible for flowers, fruits and seeds pigmentation, protection against UV, defense against pathogens and signal transduction during stress. Mutant plants, defficient in chalcone synthase and chalcone isomerase that are unable to accumulate flavonoids have been demonstrated to be more sensitive to UV light [125]. Many genes encoding flavonoid biosynthesis components are induced under stress conditions. Considerable increase in flavonoid level has been demonstrated in response to abiotic stresses such as wounding, drought and nutrient deprivation [126].

Under steady state conditions, ROS are eliminated by antioxidative mechanisms described above (78). Different abiotic and biotic stresses such as drought, high salinity, heavy metals, high light, UV radiation, high/low temperature or pathogen attack may disturb the balance between the ROS production and scavenging. The equilibrium between ROS production and scavenging influences their mode of action as protective, signaling or damaging factors. The increase in cellular ROS level can cause significant damage to cell structures, cell death and in consequence loss in crop production [127]. The vast role of ROS in the response to environmental conditions and cell-death signaling are well documented $[65,128]$. There are results suggesting that $\mathrm{H}_{2} \mathrm{O}_{2}$ antagonizes the ${ }^{1} \mathrm{O}_{2}$-mediated signaling and that the cross-talk between signaling pathways, transferred by different ROS, may contribute to the overall response of plant exposed to adverse environmental conditions [129]. Moreover, ROS interact with several other signaling pathways including NO and hormones like SA, JA and ET. Such interactions and the ROS/hormonal balance determine whether the cell will stay alive or enter the PCD pathway $[14,39,60]$. Finally, the role of ROS as messenger molecules cannot be underestimated, since it has been demonstrated that they trigger the transduction of stress signals and systemic acclimation to adverse environmental conditions $[130,131]$.

\section{High and excess light stress}

Light is an essential factor in the regulation of plant growth, development and stress responses but it is also responsible for the production of reactive oxygen species leading to PCD. The cell death phenotype of many lesion mimic mutants of Arabidopsis thaliana and Zea mays is dependent on light [132-134]. Plant cells have been equipped with sophisticated light-perception mechanisms and signaling pathways that are very important for the plant defense. Three families of photoreceptors collecting different light qualities exist in plant cells: phytochromes (PHY), cryptochromes (CRY) and phototropins (PHOT). They localize in the plasma membrane, cytoplasm or nucleus. While photoreceptors play mainly a regulatory role, providing information about diurnal and seasonal light-quality changes, the lightquantity sensing system is located in chloroplasts. The absorption of photons by photosynthetic apparatus is possible owing to chlorophylls located in light-harvesting complexes (LHCs) of photosystem II (PSII) and photosystem I (PSI) in the thylakoid membrane 
of chloroplasts. PSII is enriched in chlorophyll b molecules which results in a maximum absorption at the orange/red light spectrum $(650-680 \mathrm{~nm})$, whereas, PSI is enriched in chlorophyll a molecules and absorbs in the far red $(700 \mathrm{~nm})$. The reaction centers of PSII and PSI are coupled by a chain of electron carriers. A spectral imbalance of light may result in an unequal excitation of two photosystems, leading to increased or decreased ROS production [130]. Therefore, the distribution of light-absorbing antenna complexes between PSII and PSI is under control and can be regulated through a short-term adaptation (e.g. state transition) or long-term acclimation processes. State transition is a reversible phosphorylation of the main LHCII protein and its migration between PSII and PSI $[135,136]$. Thylakoid-associated kinase 1 (TAK1) is essential for this process since it is responsible for the phosphorylation of thylakoid proteins [137]. In contrast, long-term responses employ modifications of the photosynthetic complexes structure through the adjustment of LHCII and PSII size or PSI/PSII ratio $[138,139]$. Both short-and long-term processes are triggered by the perception of imbalanced photosystem excitation via redox signals that come from the photosynthetic electron transport (PET) chain, especially from one of electron carriers - plastoquinone (PQ) $[130,140]$.

In natural environment, plants are often exposed to high light (HL) intensities that lead to the absorption of more light energy than can be used for carbon dioxide fixation [77]. The amount of absorbed light energy that is excessive and cannot be used for photosynthetic metabolism is termed excess excitation energy (EEE) [77,130]. In response to EEE, there is an immediate increase in the electron transport rate and in consequence redox changes of PET components. Alterations in the redox status of PET, especially the reduction of PQ pool leads to the expression deregulation of nuclear and chloroplastic genes that encode photosynthesis components such as LHC proteins [141-143] and antioxidants like APX [144,145]. The response to EEE involves not only the alteration in photosynthetic flux but it is also accompanied by changes in the water status and temperature of the leaf, and in consequence it is associated with elevated ABA levels, changes in the redox state of glutathione pool and increased activity of heat shock transcription factors [146,147]. If the accumulation of ROS exceeds the ability of removing them by antioxidant systems, it may cause a photooxidative damage of the photosynthetic apparatus which may lead to cell death, manifested by bleaching, chlorosis or bronzing of leaves [148]. Therefore, the avoidance of EEE, its dissipation and HL tolerance are fundamental for the plant survival. EEE-mediated PCD can be considered as a beneficial process, as it triggers signal transduction to systemic cells and their acclimation to high light $[130,131]$.

Avoidance strategies include such processes as: movements of chloroplasts, decrease in the number of photosynthetic reaction centers, curling of leaves and increase in the thickness of cuticular wax [149]. During HL treatment, chloroplasts have been demonstrated to move to the anticlinal wall (Figure 5) and this response has been proven to be mediated by blue/UVA receptors [150]. 

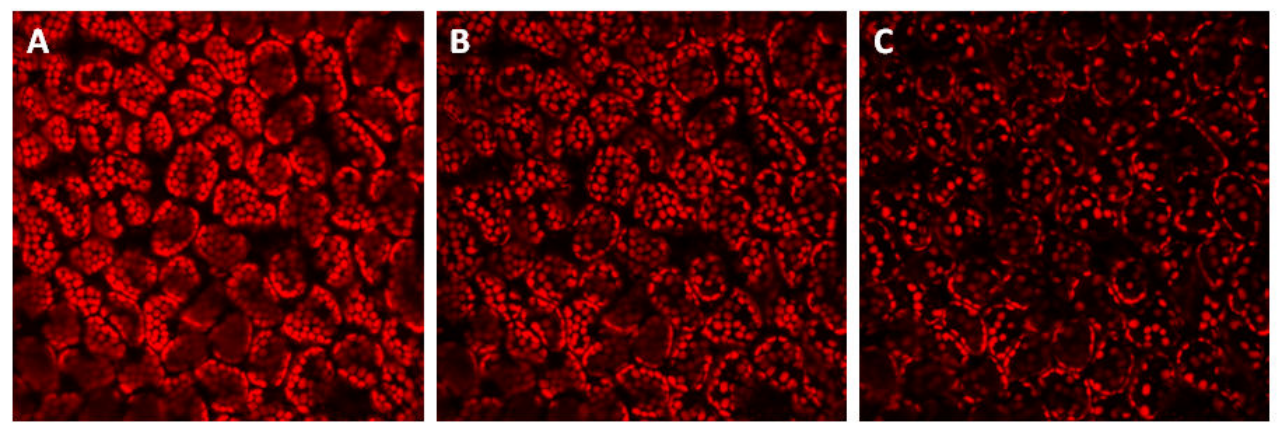

Figure 5. Chloroplast high light avoidance movements. Dark-acclimated Arabidopsisthaliana leaf strips have been exposed to a laser beam and the autofluorescence of chloroplasts has been recorded directly after switching on the laser (A), 7 min (B) and $30 \mathrm{~min}(C)$ after laser exposure.

Plants have also developed several mechanisms for removing the excess of energy. Dissipation of EEE can be achieved by the combination of photochemical (qP) and non-photochemical quenching (NPQ) processes. Photochemical quenching increases the utilization of photosynthetic electrons by metabolic pathways such as the water-water cycle or photorespiration. The consumption of electrons through water-water cycle is achieved by combined action of the $\mathrm{O}_{2}$ reduction at PSI to $\mathrm{O}_{2}{ }^{-}$and the chloroplast antioxidant system. The reduction of $\mathrm{O}_{2}$ is much lower than the disproportionation of $\mathrm{O}_{2}^{-}$, catalysed by SOD and the following $\mathrm{H}_{2} \mathrm{O}_{2}$ processing to $\mathrm{H}_{2} \mathrm{O}$, catalysed by APX. Therefore, the water-water cycle shortens the lifetime of $\mathrm{O}_{2}^{-}$and $\mathrm{H}_{2} \mathrm{O}_{2}$, suppresses the production of ${ }^{\bullet} \mathrm{OH}$, and prevents photoinhibition [77]. Another energy sink preventing photoinhibition of photosynthetic apparatus by EEE is photorespiration. During this process, photo-produced ATP and reducing equivalents are consumed, preventing the overreduction of PET. However, the photorespiratory cycle leads to the production of $\mathrm{H}_{2} \mathrm{O}_{2}$ that has to be elimainated by antioxidant systems [151].

Non-photochemical quenching processes relay on the transfer of excitation energy to carotenoids that are able to dissipate it as heat during the xanthophyll cycle (VAZ cycle). The xanthophyll cycle involves the conversion of violaxanthin to de-epoxidised zeaxanthin, via the intermediate antheraxanthin. This enzymatic cycle is performed by violaxanthin de-epoxidase and plays a key role in the stimulation of energy dissipation within light-harvesting antenna [152]. In Arabidopsis, the chlorophyll binding protein - PSII subunit S, encoded by PsbS gene has been proven to be required for NPQ [153].

Excess energy is sensed by the photosynthetic apparatus not only as a result of HL, but also other environmental factors such as UV radiation, limitations in nutrient availability, drought, salinity or high/low temperatures. All these abiotic stimuli are accompanied by oxidative stress, manifested in the overproduction of reactive oxygen species. If the level of ROS is too high for antioxidant system to eliminate them, cellular macromolecules and structures can be damaged, which triggers PCD. Several studies clearly demonstrate that 
programmed cell death is affected by light. The spread of wound-induced PCD in maize tissue has been shown to be transmitted by chloroplast-produced ROS [134]. It has also been found that the HR-mediated cell death is accelerated by the loss of chloroplast function [154]. Moreover, a study using light- and dark-grown plant cell culture has proven that they respond differently to PCD-inducing stimuli, resulting in various levels of DNA fragmentation and cell-content condensation [65]. Direct induction of programmed cell death by exposure of Arabidopsis rosettes to excess light (EL) $\left(2000 \mu \mathrm{mol}\right.$ of photons $\left.\mathrm{m}^{-2} \mathrm{~s}^{-1}\right)$ has also been demonstrated [130].

Although ROS produced during the progress of PCD are damaging for the cell, they are also needed as messenger molecules preparing other cells for a struggle with stress conditions. $\mathrm{H}_{2} \mathrm{O}_{2}$ is thought to freely diffuse across biological membranes, thus it has been proposed to directly influence the function of extra-chloroplastic signaling components. The possibility that $\mathrm{H}_{2} \mathrm{O}_{2}$ acts as an intracellular messenger molecule has been suggested since it triggeres systemic response to EL [130]. When low-light-grown Arabidopsis rosettes have been partially exposed to EL, unexposed leaves have become acclimated to EEE and to photooxidative stress. This phenomenon, termed systemic acquired acclimation (SAA) is attributed to chloroplasts, as it is associated with specific changes in redox status of the photosynthetic electron carrier chain. Such redox changes lead to the alternation in transcription profiles, triggering SAA. By the use of photosynthesis inhibitors: 3,4-dichlorophenyl-1,1-dimethylurea (DCMU), which blocks the reduction of PQ and 2,5-dibromo-3-methyl-6-isopropyl-p-benzoquinone (DBMIB), that blocks PQ oxidation, it has been demonstrated that the PQ pool redox status is predominantly responsible for SAA $[60,130]$. DCMU has been also proven to inhibit effects of EEE, such as higher NPQ, production of ET, $\mathrm{H}_{2} \mathrm{O}_{2}$ and decrease in stomatal conductance. On the other hand, DBMIB has been shown to trigger the production of ET, $\mathrm{H}_{2} \mathrm{O}_{2}$ and stomatal closure even under low light. These results indicate that the redox status of PQ pool and NPQ play a critical role in the initiation of response to EEE, in ET and $\mathrm{H}_{2} \mathrm{O}_{2}$ signaling and consequently in the PCD regulation [11,60,130,155,156]. Activation of the SAdependent pathway in response to EEE has been also observed after an initial induction of ROS/ET signaling [60]. Other hormones such as JA and ABA, synthesized at least partially within the chloroplast, also participate in response to EEE [149]. A large number of transcripts encoding different antioxidant defense enzymes is induced in local and systemic leaves after EL treatment. Apart from APX1 and APX2 [130], higher expression level has been proven for GPX2, GSTs, APX3 and CSD1 [60,157]. Furthermore, a recent study has suggested that local and systemic responses to EL are associated with changes in the plasma membrane electrical potential (photoelectrophysiological signaling - PEPS). During the EL incident, PEPS has been shown to be initiated by quantum redox changes in PSII, transduced by bundle sheath cells and its systemic propagation has been proven to be dependent on APX2 function. Therefore, PEPS is suggested as a new component of signaling cascades that regulate light acclimatory responses. Furthermore, it has been proposed that leaves are able to memorize different EL episodes and use this information for improving their acclimation and survival under prolonged periods of unfavorable light conditions [131]. 
In the last decade a significant progress has been made in improving light-induced oxidative stress tolerance in plants. Various components of antioxidative system involved in ROS scavenging have been up- or down-regulated to develop transgenic lines with altered antioxidants levels. Overexpression of enzymes involved in AsA biosynthesis has been shown to confer oxidative stress tolerance in tomato plants [158]. Increased AsA content has been also demonstrated to enhance high light stress tolerance in Arabidopsis [159]. Higher concentration of GSH has proven to protect potato plants against oxidative damage [160]. Moreover, reduced level of light-mediated cellular damage has been observed in transgenic tobacco plants overexpressing chloroplast-localized Cu/Zn-SOD (161) and thylakoid membrane-bound APX [162]. MDHAR overexpression in Arabidopsis has been demonstrated to enhance the tolerance towards photooxidative stresses [163]. Moreover, some studies have reported that combined expression of antioxidant enzymes in transgenic plants acts synergistically on stress tolerance, e.g. simultaneous overexpression of $\mathrm{Cu} / \mathrm{Zn}-\mathrm{SOD}$ and APX in tobacco chloroplasts enhances the resistance to the photooxidative stress in comparison to their single overexpression [164].

\section{UV radiation stress}

Being exposed to sunlight, plants need to deal with the damaging effect of ultraviolet (UV) radiation which reduces the genome stability, impeding their growth and productivity. These effects result from damage to cell components including not only nucleic acids, but also proteins and membrane lipids. Upon UV exposure, strongly mutagenic cross-linked forms of DNA can be produced [165]. In order to minimize effects of UV radiation, plants accumulate UV-absorbing secondary metabolites, perform the monomerization of UV-induced pyrimidine dimers (DNA repair) and neutralize generated ROS [166,167].

UV radiation consists of UV-C (below $280 \mathrm{~nm}$ ), UV-B (280-320 nm) and UV-A (320-390). Although UV-C is not physiologically relevant to plants since it is efficiently blocked by the stratosphere, the UV-C-triggered cell damage is comparable to induced with UV-B radiation, which reaches Earth's surface [168]. Therefore, UV-C radiation has been widely used to study DNA damage and repair mechanisms upon UV stress [169].

UV has been demonstrated to trigger apoptosis in animals [170] and apoptosis-like changes in Arabidopsis, including DNA laddering, changes in nucleus morphology (crescent shape) and its fragmentation [168]. It has been also proven to induce oxidative burst in plant cells [171], considered as the main cause of cell death, which aims at the limitation of damage spreading. Light is necessary for UV-C-triggered cell death and caspase-like proteases participate in this process since caspase-inhibitors are able to block the onset of DNA fragmentation $[25,172]$. Recent study performed on Arabidopsis protoplasts has shown that during the early stage of UV stress, a burst of ROS in chloroplasts and adjacent mitochondria is detected. Mitochondria dysfunction has been also observed, manifested by changes in their distribution, mobility and the loss in mitochondrial transmembrane potential. Moreover, the pre-incubation with antioxidant molecule - ascorbic acid or inhibitor of photosynthetic elec- 
tron transport - DCMU decreases the ROS production and retards PCD. These results prove that mitochondria and ROS act as mediators in the UV-C-induced cell death [173] and that AsA can be considered as an important antioxidant during this process [174], which is consistent with what has been reported in various types of PCD. It has been also shown that Arabidopsis proteins AtDAD1 and AtDAD2 (defender against apoptotic death), localized in the endoplasmic reticulum membrane can suppress DNA fragmentation, indicating an involvement of the ER in UV-C-triggered PCD pathway (25). The microarray approach has identified numerous genes responsible for ROS scavenging, signaling, transcription regulation and involved in DNA replication or conformation changes that have been deregulated after exposure to UV-C radiation [175]. Metacaspase-8 (AtMC8) has been proven to be strongly up-regulated by UV-C. Overexpression of AtMC8 in Arabidopsis has resulted in more severe cell death, while knocking-out AtMC8 has reduced the UV-C-triggered PCD, which suggests that metacaspase- 8 is a part of PCD pathway activated by UV radiation [176]. The activation of PCD program upon UV helps plants in eliminating damaged cells to control cell quality and quantity after the trauma.

\section{Drought stress - soil water deficit}

Drought is one of the most unfavorable environmental factors that affects growth and development of plants and consequently limits plant productivity. Plants have developed specific acclimation and adaptation mechanisms to survive the soil water deficit. In response to drought, plants can exhibit either escape (ability to complete the life cycle before severe stress) or resistance mechanisms. Resistance mechanisms include drought avoidance and drought tolerance. The latter depends on the cell turgor maintenance by accumulating osmolytes and soluble sugars [177]. There are several examples of molecules that help to maintain an osmotic balance under dehydration conditions: sugars, polyols and proline [178]. Proline is accumulated in the cytoplasm and chloroplast stroma while other solutes (sugars, organic acids, potassium) are cumulated in the vacuole. When the cellular water content decreases, they stabilize cellular structures through hydrophilic interactions and hydrogen bonding [179]. A similar role is fulfilled by late embryogenesis abundant (LEA) proteins - a family of unstructured proteins. LEA proteins accumulate in response to dehydration and ABA treatment. Because of their high hydrophilicity and solubility in water, it has been proposed that they play a role in protecting cytoplasmic structures during dehydration [180]. The avoidance mechanism is possible by the maintenance of high water potential in plant tissue despite soil water deficit. It can be achieved by: improved water uptake under stress, the ability to hold water as well as by the reduction of its loss through smaller leaf area and lesser stomatal and cuticular conductance. One of the first acclimation responses to drought is the decrease in leaf growth, which helps to maintain the cell turgor and reduces the transpiration area. In Arabidopsis, the size of leaf is regulated by both cell division and cell expansion. Under drought stress, Arabidopsis leaves have been demonstrated to compensate for the low rate of expansion by the extension of expansion duration [181]. The cell expansion is a process of cell wall loosening performed by enzymatic and non-enzymatic compo- 
nents, from which expansins are key proteins engaged in this process. The onset of cell expansion involves pumping of protons into the cell wall, which makes the surrounding more acidic. As a result, expansins become activated. They loosen connections between cellulose microfibrils, which leads to the cell wall relaxation, water uptake and consequently the cell expansion [182]. It has been demonstrated that the mild osmotic stress causes the induction of expansin genes [183].

Photosynthesis is one of major processes affected by water deficit since stomata closure causes reduced $\mathrm{CO}_{2}$ diffusion to the chloroplast. As a result of the inhibition of photosynthesis and the predominance of photorespiration, ROS are generated [184]. It has been demonstrated that in drought-stressed plants, the ABA-controlled stomata closure is mediated by $\mathrm{H}_{2} \mathrm{O}_{2}$ [185]. Under severe drought stress, some antioxidant enzymes have been shown to be highly induced [186]. However, studies on many drought-stressed crop species showed an inconsistency in their expression since in some cases they have been induced, but in other repressed, suggesting that different ROS balance may be required during different response phases [187].

During water deficit, ROS are responsible for the induction of leaf senescence, which is executed through the programmed cell death and plays an important role in the plant survival. It contributes to the nutrients remobilisation during stress and allows the rest of plant to benefit from them and stay alive. Drought-induced PCD enables also the abscission of some leaves and thus the avoidance of further water loss through the transpiration. It occurs gradually and is manifested by specific biochemical and molecular changes such as chromatin condensation, thylakoid swelling, lipid peroxidation, degradation of chlorophyll (leaf yellowing) and proteins. Apart from ROS, cytokinins and ABA have been shown to be involved in the regulation of water-deficit-triggered senescence [123]. Recent studies have shown that the water deficit triggers PCD not only in green tissues but also in plant root tips. Apical meristem cells of primary roots undergoing PCD, demonstrate increased size of vacuole, degradation of organelles and the collapse of plasma membrane [188].

Early events in the perception of drought stress signals include the activation of transcription factors belonging to such classes as DREB/CBF (e.g. DREB1a, DREB2a), ABF (e.g. ABF2, ABF4), MYB (e.g. MYB2), MYC, NAC and WRKY. Many of them possess stress responsive cis-regulatory elements in their promoter sequences like abscisic acid-responsive elements (ABRE) and drought-responsive elements (DRE) [189-191]. The plasma membrane-associated NTL4 (NAC transcription factor) after drought or ABA treatment has been shown to be proteolytically activated and transported to the nucleus where it induces expression of NADPH oxidase involved in ROS generation [192]. Moreover, the dehydration stimulates expression of BAX inhibitor-1 (AtBI-1). The atbi1 mutant has been shown to display more severe cell death, indicating that ER-located AtBI-1 modulates the water-deficit-induced PCD [188]. Drought stress has been also proven to regulate the expression and activity of aquaporins - a family of channel proteins that facilitate the transport of water along transmembrane water potential gradients [193].

Upon soil water deficit, the accumulation of ABA and the induction of ABA-associated signaling genes occur. ABA induces various second messengers such as cytosolic $\mathrm{Ca}^{2+}$, ROS 
and NO in guard cells. These signals evoke ion efflux through plasma membrane ion channels, resulting in the reduction of guard cell turgor pressure and stomata closure to reduce water loss through the transpiration [194]. Mutants with the perturbation of ABA synthesis or signaling display drought hypersensitivity, manifested in significant growth reduction which suggests that ABA is needed for the proper response to drought [177]. In Arabidopsis, stomata closure has been shown to be regulated by $A B I 1$ and $A B I 3$ ( $A B A$-insensitive 1 and 3) belonging to a group of genes identified through mutant screens and being associated with ABA-mediated metabolic responses to stress. Under drought, $A B I 1$ transcription is up-regulated while $A B I 3$ is usually down-regulated. Recently, $A B I 3$ has been hypothesized to be essential for the successful drought recovery [195]. The cell-surface ABA receptors have not been recognized yet. However, a recent study has proposed the flowering time control protein $\mathrm{A}$ (FCA) and the chloroplastic magnesium protoporphyrin-IX chelatase $\mathrm{H}$ subunit $(\mathrm{CHLH})$ as candidates for ABA receptors, both of which have been shown to bind ABA in vitro [196]. Two genes have been found to play a crucial role in the prevention of stomata opening - GPA1 (G PROTEIN ALPHA SUBUNIT 1) and PLD 1 (PHOSPHOLIPASE D AL$P H A$ 1) [197]. PLD-produced phosphatidic acid has been also shown to play an important role in the plant response to drought stress [198].

Similarly to ABA, JA also triggers stomata closure and such response is conserved among various plant species [199]. At the early stage of moderate drought, plants accumulate high concentrations of ABA and induce ABA-responsive genes. At this stage, no significant differences in JA-responsive genes are observed. At later stage of drought stress, ABA level returns to normal, while JA synthesis and JA signaling genes are significantly downregulated. This suggests the negative correlation between ABA and JA pathways [177]. The high concentration of JA is probably undesirable during drought stress, as it inhibits the cell expansion and results in stunted growth [200]. Therefore, plants down-regulate JA synthesis and signaling pathways to minimize the inhibitory effect of JA on growth, establishing a new hormone homeostasis.

Downstream of early stress perception events, signaling molecules are activated. Such secondary messengers include $\mathrm{Ca}^{2+}$ ions and ROS. They induce further genes that are needed to establish a new cellular homeostasis leading to drought resistance and tolerance [180]. Recent studies have strongly proven that drought response progresses through mitogen-activated protein kinase (MAPK) pathways [201]. In yeast and animals, MAPK-regulated pathways take part in the production of osmolytes and antioxidants. These MAPK pathways are activated by receptors/sensors such as protein tyrosine kinases, G-protein-coupled receptors and histidine kinases. Among these, G-protein-associated receptors have been proposed to serve as one kind of membrane-bounded receptors for ABA. A family of histidine kinases (HK) have been also identified in plants [199]. An Arabidopsis AtHK1 has been suggested to be involved in the osmotic stress signal transduction [202]. Other members of this family, ATHB7 and ATHB12 have been proposed to maintain the reduction of plant growth under drought, which is an acclimation response to survive prolonged drought stress [177]. 
The elucidation of mechanisms controlling drought stress responses has enabled to engineer plants by the expression of specific stress-related genes. Although it was believed that the modulation of osmoregulatory genes would be the best strategy, attempts failed to result in any significant drought-stress tolerance improvement [203]. However, constitutive expression of some LEA proteins has conferred tolerance to soil water deficit in transgenic rice [204] and wheat [205]. Moreover, tomato plants overexpressing Arabidopsis CBF1 (DREB1B) have exhibited improved drought tolerance [206]. Similar results have been obtained for transgenic Arabidopsis and rice plants overexpressing stress-responsive NAC genes [207].

\section{Conclusions}

Plants have evolved various strategies to acclimate to different environmental stresses. The most fundamental strategy is the development of high plasticity of plant tissues. It has been demonstrated that programmed cell death plays an important role in this plasticity and subsequent adaptation to unfavorable conditions. There is a growing evidence that PCD is a crucial process in both morphogenetic changes execution and the following adaptation. Although each decade brings a vast number of research, our understanding of plant PCD and its underlying mechanisms is still in its early stage. Further insight into details of the PCD molecular machinery in plants is important, since it is an attractive target for improving stress tolerance and plant yield under adverse conditions. Essentially, it could lead to the generation of pathogen-resistant and stress-tolerant crops as well as fruit varieties with an extended shelf life.

\section{Acknowledgments}

This work was supported by the Welcome/2008/1 Program operated within the framework of the Foundation for Polish Science, co-financed by the European Regional Development Fund.

\section{Abbreviations}

ABA - abscisic acid; AOX - alternative oxidase; APX - ascorbate peroxidase; AsA - ascorbic acid; BI - Bax-Inhibitor; CAT - catalase; Chl - chlorophyll; DBMIB - 2,5-dibromo-3-methyl-6isopropyl-p-benzoquinone; DCMU - 3,4-dichlorophenyl-1,1-dimethylurea; DHA - dehydroascorbate; DHAR - dehydroascorbate reductase; EEE - excess excitation energy; EL excess light; ER - endoplasmic reticulum; ET - ethylene; ETC - electron transport chain; FAD - flavin adenine dinucleotide; GA - gibberellic acid; GPX - glutathione peroxidase; GR - glutathione reductase; GSH - reduced glutathione; GSSG - oxidized glutathione; GST - glutathione-S- transferase; HL - high light; IAP - inhibitor of apoptosis; JA - jasmonic acid; HR - 
hypersensitive response; LEA - late embryogenesis abundant; LHC - light-harvesting complex; LPO - lipid peroxidation; LSD1 - LESION SIMULATING DISEASE 1; MC - metacaspase; MDA - malonyldialdehyde; MDHAR - monodehydroascorbate reductase; MeJA methyl-jasmonic acid; MAPK - mitogen-activated protein kinase; NADPH - nicotinamide adenine dinucleotide phosphate; NO - nitric oxide; NPQ - non-photochemical quenching; PA - phosphatidic acid; PCD - programmed cell death; PEPS - photoelectrophysiological signaling; PET - photosynthetic electron transport; PG - phosphoglycolate; PGA - phosphoglycerate; PLD - phospholipase D; PSI and PSII - photosystem I and II; PQ - plastoquinone; PUFA - polyunsaturated fatty acids; qP - photochemical quenching; RCD - runaway cell death; RNS - reactive nitrogen species; ROS - reactive oxygen species; Rubisco - ribulose-1,5bisphosphate carboxylase/oxygenase; RuBP - ribulose-1,5-bisphosphate; SA - salicylic acid; SAA - systemic acquired acclimation; SAR - systemic acquired resistance; SOD - superoxide dismutase; TF - transcription factor; UV - ultraviolet radiation; VPE - vacuolar processing enzyme; XOD - xanthine oxidase.

\section{Author details}

Weronika Wituszyńska and Stanisław Karpiński

*Address all correspondence to: weronika_wituszynska@sggw.pl

Department of Plant Genetics, Breeding and Biotechnology, Warsaw University of Life Sciences, Warsaw, Poland

\section{References}

[1] Pennell RI, Lamb C. Programmed Cell Death in Plants. Plant Cell. 1997;9(7):1157-68.

[2] Fukuda H. Programmed cell death of tracheary elements as a paradigm in plants. Plant Mol. Biol. 2000;44(3):245-53.

[3] Dellaporta SL, Calderon-Urrea A. Sex determination in flowering plants. Plant Cell. 1993;5(10):1241-51.

[4] Gunawardena AHLAN, Greenwood JS, Dengler NG. Programmed cell death remodels lace plant leaf shape during development. Plant Cell. 2004;16(1):60-73.

[5] Gunawardena AHLAN. Programmed cell death and tissue remodelling in plants. J. Exp. Bot. 2008;59(3):445-51.

[6] Gan S, Amasino RM. Making Sense of Senescence (Molecular Genetic Regulation and Manipulation of Leaf Senescence). Plant Physiol. 1997;113(2):313-9.

[7] Williams B, Dickman M. Plant programmed cell death: can't live with it; can't live without it. Mol. Plant Pathol. 2008;9(4):531-44. 
[8] Dietrich RA, Delaney TP, Uknes SJ, Ward ER, Ryals JA, Dangl JL. Arabidopsis mutants simulating disease resistance response. Cell. 1994;77(4):565-77.

[9] Dangl JL, Dietrich RA, Richberg MH. Death Don't Have No Mercy: Cell Death Programs in Plant-Microbe Interactions. Plant Cell. 1996;8(10):1793-807.

[10] Lam E. Controlled cell death, plant survival and development. Nat. Rev. Mol. Cell Biol. 2004;5(4):305-15.

[11] Mateo A, Mühlenbock P, Rustérucci C, Chang CC-C, Miszalski Z, Karpinska B, et al. LESION SIMULATING DISEASE 1 is required for acclimation to conditions that promote excess excitation energy. Plant Physiol. 2004;136(1):2818-30.

[12] Coll NS, Epple P, Dangl JL. Programmed cell death in the plant immune system. Cell Death Differ. 2011;18(8):1247-56.

[13] Evans DE. Aerenchyma formation. New Phytologist. 2004;161(1):35-49.

[14] Mühlenbock P, Plaszczyca M, Plaszczyca M, Mellerowicz E, Karpinski S. Lysigenous aerenchyma formation in Arabidopsis is controlled by LESION SIMULATING DISEASE1. Plant Cell. 2007;19(11):3819-30.

[15] Swidzinski JA, Sweetlove LJ, Leaver CJ. A custom microarray analysis of gene expression during programmed cell death in Arabidopsis thaliana. Plant J. 2002;30(4): 431-46.

[16] Muñoz-Pinedo C. Signaling pathways that regulate life and cell death: evolution of apoptosis in the context of self-defense. Adv. Exp. Med. Biol. 2012;738:124-43.

[17] Mittler R, Simon L, Lam E. Pathogen-induced programmed cell death in tobacco. J. Cell. Sci. 1997;110:1333-44.

[18] Samuilov VD, Lagunova EM, Kiselevsky DB, Dzyubinskaya EV, Makarova YV, Gusev MV. Participation of chloroplasts in plant apoptosis. Biosci. Rep. 2003;23(2-3): 103-17.

[19] Hatsugai N, Kuroyanagi M, Nishimura M, Hara-Nishimura I. A cellular suicide strategy of plants: vacuole-mediated cell death. Apoptosis. 2006;11(6):905-11.

[20] Torres MA, Dangl JL. Functions of the respiratory burst oxidase in biotic interactions, abiotic stress and development. Curr. Opin. Plant Biol. 2005;8(4):397-403.

[21] Chen S, Dickman MB. Bcl-2 family members localize to tobacco chloroplasts and inhibit programmed cell death induced by chloroplast-targeted herbicides. J. Exp. Bot. 2004;55(408):2617-23.

[22] Lam E, Pozo O del. Caspase-like protease involvement in the control of plant cell death. Plant Molecular Biology. 2000;44(3):417-28.

[23] del Pozo O, Lam E. Caspases and programmed cell death in the hypersensitive response of plants to pathogens. Curr. Biol. 1998;8(20):1129-32. 
[24] De Jong AJ, Hoeberichts FA, Yakimova ET, Maximova E, Woltering EJ. Chemical-induced apoptotic cell death in tomato cells: involvement of caspase-like proteases. Planta. 2000;211(5):656-62.

[25] Danon A, Rotari VI, Gordon A, Mailhac N, Gallois P. Ultraviolet-C overexposure induces programmed cell death in Arabidopsis, which is mediated by caspase-like activities and which can be suppressed by caspase inhibitors, p35 and Defender against Apoptotic Death. J. Biol. Chem. 2004;279(1):779-87.

[26] Vercammen D, Cotte B van de, Jaeger GD, Eeckhout D, Casteels P, Vandepoele K, et al. Type II Metacaspases Atmc4 and Atmc9 of Arabidopsis thaliana Cleave Substrates after Arginine and Lysine. J. Biol. Chem. 2004;279(44):45329-36.

[27] Watanabe N, Lam E. Two Arabidopsis metacaspases AtMCP1b and AtMCP2b are arginine/lysine-specific cysteine proteases and activate apoptosis-like cell death in yeast. J. Biol. Chem. 2005;280(15):14691-9.

[28] Zhang Y, Lam E. Sheathing the swords of death: post-translational modulation of plant metacaspases. Plant Signal Behav. 2011;6(12):2051-6.

[29] Watanabe N, Lam E. Arabidopsis metacaspase $2 \mathrm{~d}$ is a positive mediator of cell death induced during biotic and abiotic stresses. Plant J. 2011;66(6):969-82.

[30] Coll NS, Vercammen D, Smidler A, Clover C, Van Breusegem F, Dangl JL, et al. Arabidopsis type I metacaspases control cell death. Science. 2010;330(6009):1393-7.

[31] Lacomme C, Cruz SS. Bax-induced cell death in tobacco is similar to the hypersensitive response. PNAS. 1999;96(14):7956-61.

[32] Mitsuhara I, Malik KA, Miura M, Ohashi Y. Animal cell-death suppressors Bcl-x(L) and Ced-9 inhibit cell death in tobacco plants. Curr. Biol. 1999;9(14):775-8.

[33] Lincoln JE, Richael C, Overduin B, Smith K, Bostock R, Gilchrist DG. Expression of the antiapoptotic baculovirus p35 gene in tomato blocks programmed cell death and provides broad-spectrum resistance to disease. PNAS. 2002;99(23):15217-21.

[34] Li W, Dickman MB. Abiotic stress induces apoptotic-like features in tobacco that is inhibited by expression of human Bcl-2. Biotechnol. Lett. 2004;26(2):87-95.

[35] Sanchez P, de Torres Zabala M, Grant M. AtBI-1, a plant homologue of Bax inhibitor-1, suppresses Bax-induced cell death in yeast and is rapidly upregulated during wounding and pathogen challenge. Plant J. 2000;21(4):393-9.

[36] Kawai-Yamada M, Jin L, Yoshinaga K, Hirata A, Uchimiya H. Mammalian Bax-induced plant cell death can be down-regulated by overexpression of Arabidopsis Bax Inhibitor-1 (AtBI-1). PNAS. 2001;98(21):12295-300.

[37] Watanabe N, Lam E. Arabidopsis Bax inhibitor-1 functions as an attenuator of biotic and abiotic types of cell death. Plant J. 2006;45(6):884-94. 
[38] Janda T, Horváth E, Szalai G, PáLdi E. Role of Salicylic Acid in the Induction of Abiotic Stress Tolerance. In: Hayat S, Ahmad A, editors. Salicylic Acid: A Plant Hormone. Springer Netherlands; 2007 p. 91-150

[39] Overmyer K, Brosché M, Kangasjärvi J. Reactive oxygen species and hormonal control of cell death. Trends Plant Sci. 2003;8(7):335-42.

[40] Alvarez ME. Salicylic acid in the machinery of hypersensitive cell death and disease resistance. Plant Mol. Biol. 2000;44(3):429-42.

[41] Leon J, Lawton MA, Raskin I. Hydrogen Peroxide Stimulates Salicylic Acid Biosynthesis in Tobacco. Plant Physiol. 1995;108(4):1673-8. [

[42] Draper J. Salicylate, superoxide synthesis and cell suicide in plant defence. Trends in Plant Science. 1997;2(5):162-5.

[43] Delledonne M, Zeier J, Marocco A, Lamb C. Signal interactions between nitric oxide and reactive oxygen intermediates in the plant hypersensitive disease resistance response. PNAS. 2001;98(23):13454-9.

[44] John I, Drake R, Farrell A, Cooper W, Lee P, Horton P, et al. Delayed leaf senescence in ethylene-deficient ACC-oxidase antisense tomato plants: molecular and physiological analysis. The Plant Journal. 1995;7(3):483-90.

[45] Overmyer K, Tuominen H, Kettunen R, Betz C, Langebartels C, Sandermann H Jr, et al. Ozone-sensitive arabidopsis rcd1 mutant reveals opposite roles for ethylene and jasmonate signaling pathways in regulating superoxide-dependent cell death. Plant Cell. 2000;12(10):1849-62.

[46] Turner JG, Ellis C, Devoto A. The jasmonate signal pathway. Plant Cell. 2002;14 Suppl:S153-164.

[47] Seo HS, Song JT, Cheong J-J, Lee Y-H, Lee Y-W, Hwang I, et al. Jasmonic acid carboxyl methyltransferase: A key enzyme for jasmonate-regulated plant responses. PNAS. 2001;98(8):4788-93.

[48] Zhang L, Xing D. Methyl jasmonate induces production of reactive oxygen species and alterations in mitochondrial dynamics that precede photosynthetic dysfunction and subsequent cell death. Plant Cell Physiol. 2008;49(7):1092-111.

[49] Fath A, Bethke PC, Jones RL. Enzymes That Scavenge Reactive Oxygen Species Are Down-Regulated Prior to Gibberellic Acid-Induced Programmed Cell Death in Barley Aleurone. Plant Physiol. 2001;126(1):156-66.

[50] Steffens B, Sauter M. Epidermal Cell Death in Rice Is Regulated by Ethylene, Gibberellin, and Abscisic Acid. Plant Physiol. 2005;139(2):713-21.

[51] Levine A, Pennell RI, Alvarez ME, Palmer R, Lamb C. Calcium-mediated apoptosis in a plant hypersensitive disease resistance response. Curr. Biol. 1996;6(4):427-37. 
[52] Falk A, Feys BJ, Frost LN, Jones JDG, Daniels MJ, Parker JE. EDS1, an essential component of $\mathrm{R}$ gene-mediated disease resistance in Arabidopsis has homology to eukaryotic lipases. Proc Natl Acad Sci U S A. 1999;96(6):3292-7.

[53] Jirage D, Tootle TL, Reuber TL, Frost LN, Feys BJ, Parker JE, et al. Arabidopsis thaliana PAD4 encodes a lipase-like gene that is important for salicylic acid signaling. Proc. Natl. Acad. Sci. U.S.A. 1999;96(23):13583-8.

[54] Meijer HJG, Munnik T. Phospholipid-Based Signaling in Plants. Annual Review of Plant Biology. 2003;54(1):265-306.

[55] Zhang W, Wang C, Qin C, Wood T, Olafsdottir G, Welti R, et al. The Oleate-Stimulat-

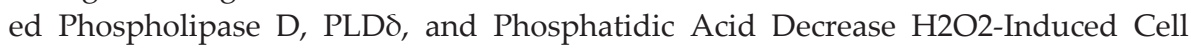
Death in Arabidopsis. Plant Cell. 2003;15(10):2285-95.

[56] Brodersen P, Petersen M, Pike HM, Olszak B, Skov S, Ødum N, et al. Knockout of Arabidopsis ACCELERATED-CELL-DEATH11 encoding a sphingosine transfer protein causes activation of programmed cell death and defense. Genes Dev. 2002;16(4): 490-502.

[57] Wiermer M, Feys BJ, Parker JE. Plant immunity: the EDS1 regulatory node. Curr. Opin. Plant Biol. 2005;8(4):383-9.

[58] Rustérucci C, Aviv DH, Holt BF, Dangl JL, Parker JE. The Disease Resistance Signaling Components EDS1 and PAD4 Are Essential Regulators of the Cell Death Pathway Controlled by LSD1 in Arabidopsis. Plant Cell. 2001;13(10):2211-24.

[59] Mateo A, Funck D, Mühlenbock P, Kular B, Mullineaux PM, Karpinski S. Controlled levels of salicylic acid are required for optimal photosynthesis and redox homeostasis. J. Exp. Bot. 2006;57(8):1795-807.

[60] Mühlenbock P, Szechynska-Hebda M, Plaszczyca M, Baudo M, Mateo A, Mullineaux PM, et al. Chloroplast signaling and LESION SIMULATING DISEASE1 regulate crosstalk between light acclimation and immunity in Arabidopsis. Plant Cell. 2008;20(9):2339-56.

[61] Jabs T, Dietrich RA, Dangl JL. Initiation of runaway cell death in an Arabidopsis mutant by extracellular superoxide. Science. 1996;273(5283):1853-6.

[62] Epple P, Mack AA, Morris VRF, Dangl JL. Antagonistic control of oxidative stressinduced cell death in Arabidopsis by two related, plant-specific zinc finger proteins. Proc. Natl. Acad. Sci. U.S.A. 2003;100(11):6831-6.

[63] Kaminaka H, Näke C, Epple P, Dittgen J, Schütze K, Chaban C, et al. bZIP10-LSD1 antagonism modulates basal defense and cell death in Arabidopsis following infection. EMBO J. 2006;25(18):4400-11.

[64] Karpinski S, Gabrys H, Mateo A, Karpinska B, Mullineaux PM. Light perception in plant disease defence signalling. Curr. Opin. Plant Biol. 2003;6(4):390-6. 
[65] Doyle SM, Diamond M, McCabe PF. Chloroplast and reactive oxygen species involvement in apoptotic-like programmed cell death in Arabidopsis suspension cultures. J. Exp. Bot. 2010;61(2):473-82.

[66] Gill SS, Tuteja N. Reactive oxygen species and antioxidant machinery in abiotic stress tolerance in crop plants. Plant Physiol. Biochem. 2010;48(12):909-30.

[67] Buchert F, Forreiter C. Singlet oxygen inhibits ATPase and proton translocation activity of the thylakoid ATP synthase CF1CFo. FEBS Lett. 2010;584(1):147-52.

[68] Hatz S, Lambert JDC, Ogilby PR. Measuring the lifetime of singlet oxygen in a single cell: addressing the issue of cell viability. Photochem. Photobiol. Sci. 2007;6(10):110616.

[69] Krieger-Liszkay A, Fufezan C, Trebst A. Singlet oxygen production in photosystem II and related protection mechanism. Photosyn. Res. 2008;98(1-3):551-64.

[70] Triantaphylidès C, Krischke M, Hoeberichts FA, Ksas B, Gresser G, Havaux M, et al. Singlet oxygen is the major reactive oxygen species involved in photooxidative damage to plants. Plant Physiol. 2008;148(2):960-8.

[71] op den Camp RGL, Przybyla D, Ochsenbein C, Laloi C, Kim C, Danon A, et al. Rapid induction of distinct stress responses after the release of singlet oxygen in Arabidopsis. Plant Cell. 2003;15(10):2320-32.

[72] Bright J, Desikan R, Hancock JT, Weir IS, Neill SJ. ABA-induced NO generation and stomatal closure in Arabidopsis are dependent on $\mathrm{H} 2 \mathrm{O} 2$ synthesis. Plant J. 2006;45(1):113-22.

[73] Mittler R, Vanderauwera S, Gollery M, Van Breusegem F. Reactive oxygen gene network of plants. Trends Plant Sci. 2004;9(10):490-8.

[74] Foreman J, Demidchik V, Bothwell JHF, Mylona P, Miedema H, Torres MA, et al. Reactive oxygen species produced by NADPH oxidase regulate plant cell growth. Nature. 2003;422(6930):442-6.

[75] Quan L-J, Zhang B, Shi W-W, Li H-Y. Hydrogen peroxide in plants: a versatile molecule of the reactive oxygen species network. J Integr Plant Biol. 2008;50(1):2-18.

[76] Vranová E, Atichartpongkul S, Villarroel R, Van Montagu M, Inzé D, Van Camp W. Comprehensive analysis of gene expression in Nicotiana tabacum leaves acclimated to oxidative stress. Proc Natl Acad Sci U S A. 2002;99(16):10870-5.

[77] Asada K. THE WATER-WATER CYCLE IN CHLOROPLASTS: Scavenging of Active Oxygens and Dissipation of Excess Photons. Annu. Rev. Plant Physiol. Plant Mol. Biol. 1999;50:601-39.

[78] Foyer CH, Noctor G. Redox homeostasis and antioxidant signaling: a metabolic interface between stress perception and physiological responses. Plant Cell. 2005;17(7): 1866-75. 
[79] Maurino VG, Peterhansel C. Photorespiration: current status and approaches for metabolic engineering. Curr. Opin. Plant Biol. 2010;13(3):249-56.

[80] Peterhansel C, Maurino VG. Photorespiration Redesigned. Plant Physiol. 2011;155(1): 49-55.

[81] Lam E, Kato N, Lawton M. Programmed cell death, mitochondria and the plant hypersensitive response. Nature. 2001;411(6839):848-53.

[82] Navrot N, Rouhier N, Gelhaye E, Jacquot J-P. Reactive oxygen species generation and antioxidant systems in plant mitochondria. Physiologia Plantarum. 2007;129(1): 185-95.

[83] Rhoads DM, Umbach AL, Subbaiah CC, Siedow JN. Mitochondrial Reactive Oxygen Species. Contribution to Oxidative Stress and Interorganellar Signaling. Plant Physiol. 2006;141(2):357-66.

[84] Maxwell DP, Wang Y, McIntosh L. The alternative oxidase lowers mitochondrial reactive oxygen production in plant cells. PNAS. 1999;96(14):8271-6.

[85] Ordog SH, Higgins VJ, Vanlerberghe GC. Mitochondrial Alternative Oxidase Is Not a Critical Component of Plant Viral Resistance But May Play a Role in the Hypersensitive Response. Plant Physiol. 2002;129(4):1858-65.

[86] Robson CA, Vanlerberghe GC. Transgenic Plant Cells Lacking Mitochondrial Alternative Oxidase Have Increased Susceptibility to Mitochondria-Dependent and -Independent Pathways of Programmed Cell Death. Plant Physiol. 2002;129(4):1908-20.

[87] del Río LA, Corpas FJ, Sandalio LM, Palma JM, Gómez M, Barroso JB. Reactive oxygen species, antioxidant systems and nitric oxide in peroxisomes. J. Exp. Bot. 2002;53(372):1255-72.

[88] Bolwell GP, Wojtaszek P. Mechanisms for the generation of reactive oxygen species in plant defence - a broad perspective. Physiological and Molecular Plant Pathology. 1997;51(6):347-66.

[89] Montillet J-L, Chamnongpol S, Rustérucci C, Dat J, van de Cotte B, Agnel J-P, et al. Fatty acid hydroperoxides and $\mathrm{H} 2 \mathrm{O} 2$ in the execution of hypersensitive cell death in tobacco leaves. Plant Physiol. 2005;138(3):1516-26.

[90] Møller IM, Jensen PE, Hansson A. Oxidative modifications to cellular components in plants. Annu Rev Plant Biol. 2007;58:459-81.

[91] Khan M, Panda S. Alterations in root lipid peroxidation and antioxidative responses in two rice cultivars under NaCl-salinity stress. Acta Physiologiae Plantarum. 2008;30(1):81-9.

[92] Ghezzi P, Bonetto V. Redox proteomics: identification of oxidatively modified proteins. Proteomics. 2003;3(7):1145-53. 
[93] Sadanandom A, Poghosyan Z, Fairbairn DJ, Murphy DJ. Differential Regulation of Plastidial and Cytosolic Isoforms of Peptide Methionine Sulfoxide Reductase in Arabidopsis. Plant Physiol. 2000;123(1):255-64.

[94] Cooke MS, Evans MD, Dizdaroglu M, Lunec J. Oxidative DNA damage: mechanisms, mutation, and disease. FASEB J. 2003;17(10):1195-214.

[95] Tuteja N, Singh MB, Misra MK, Bhalla PL, Tuteja R. Molecular mechanisms of DNA damage and repair: progress in plants. Crit. Rev. Biochem. Mol. Biol. 2001;36(4):33797.

[96] Mittler R. Oxidative stress, antioxidants and stress tolerance. Trends Plant Sci. 2002;7(9):405-10.

[97] Kliebenstein DJ, Monde R-A, Last RL. Superoxide Dismutase in Arabidopsis: An Eclectic Enzyme Family with Disparate Regulation and Protein Localization. Plant Physiol. 1998;118(2):637-50.

[98] del Río LA, Sandalio LM, Altomare DA, Zilinskas BA. Mitochondrial and peroxisomal manganese superoxide dismutase: differential expression during leaf senescence. J. Exp. Bot. 2003;54(384):923-33.

[99] Alscher RG, Erturk N, Heath LS. Role of superoxide dismutases (SODs) in controlling oxidative stress in plants. J. Exp. Bot. 2002;53(372):1331-41.

[100] Wang Y, Ying Y, Chen J, Wang X. Transgenic Arabidopsis overexpressing Mn-SOD enhanced salt-tolerance. Plant Science. 2004;167(4):671-7.

[101] Hamid Badawi G, Yamauchi Y, Shimada E, Sasaki R, Kawano N, Tanaka K, et al. Enhanced tolerance to salt stress and water deficit by overexpressing superoxide dismutase in tobacco (Nicotiana tabacum) chloroplasts. Plant Science. 2004;166(4):91928.

[102] Myouga F, Hosoda C, Umezawa T, Iizumi H, Kuromori T, Motohashi R, et al. A heterocomplex of iron superoxide dismutases defends chloroplast nucleoids against oxidative stress and is essential for chloroplast development in Arabidopsis. Plant Cell. 2008;20(11):3148-62.

[103] Simova-Stoilova L, Vaseva I, Grigorova B, Demirevska K, Feller U. Proteolytic activity and cysteine protease expression in wheat leaves under severe soil drought and recovery. Plant Physiol. Biochem. 2010;48(2-3):200-6.

[104] Matsumura T, Tabayashi N, Kamagata Y, Souma C, Saruyama H. Wheat catalase expressed in transgenic rice can improve tolerance against low temperature stress. Physiologia Plantarum. 2002;116(3):317-27.

[105] Edwards EA, Rawsthorne S, Mullineaux PM. Subcellular distribution of multiple forms of glutathione reductase in leaves of pea (Pisum sativum L.). Planta. 1990;180(2):278-84. 
[106] Sharma P, Dubey RS. Modulation of nitrate reductase activity in rice seedlings under aluminium toxicity and water stress: role of osmolytes as enzyme protectant. J. Plant Physiol. 2005;162(8):854-64.

[107] Kornyeyev D, Logan BA, Payton PR, Allen RD, Holaday AS. Elevated chloroplastic glutathione reductase activities decrease chilling-induced photoinhibition by increasing rates of photochemistry, but not thermal energy dissipation, in transgenic cotton. Functional Plant Biol. 2003;30(1):101-10.

[108] Leterrier M, Corpas FJ, Barroso JB, Sandalio LM, del Río LA. Peroxisomal Monodehydroascorbate Reductase. Genomic Clone Characterization and Functional Analysis under Environmental Stress Conditions. Plant Physiol. 2005;138(4):2111-23.

[109] Eltayeb AE, Kawano N, Badawi GH, Kaminaka H, Sanekata T, Shibahara T, et al. Overexpression of monodehydroascorbate reductase in transgenic tobacco confers enhanced tolerance to ozone, salt and polyethylene glycol stresses. Planta. 2007;225(5):1255-64.

[110] Ushimaru T, Nakagawa T, Fujioka Y, Daicho K, Naito M, Yamauchi Y, et al. Transgenic Arabidopsis plants expressing the rice dehydroascorbate reductase gene are resistant to salt stress. J. Plant Physiol. 2006;163(11):1179-84.

[111] Eltayeb AE, Kawano N, Badawi GH, Kaminaka H, Sanekata T, Morishima I, et al. Enhanced tolerance to ozone and drought stresses in transgenic tobacco overexpressing dehydroascorbate reductase in cytosol. Physiologia Plantarum. 2006;127(1):57-65.

[112] Dixon DP, Davis BG, Edwards R. Functional divergence in the glutathione transferase superfamily in plants. Identification of two classes with putative functions in redox homeostasis in Arabidopsis thaliana. J. Biol. Chem. 2002;277(34):30859-69.

[113] Dixon DP, Skipsey M, Edwards R. Roles for glutathione transferases in plant secondary metabolism. Phytochemistry. 2010;71(4):338-50.

[114] Millar AH, Mittova V, Kiddle G, Heazlewood JL, Bartoli CG, Theodoulou FL, et al. Control of ascorbate synthesis by respiration and its implications for stress responses. Plant Physiol. 2003;133(2):443-7.

[115] Yoshimura K, Miyao K, Gaber A, Takeda T, Kanaboshi H, Miyasaka H, et al. Enhancement of stress tolerance in transgenic tobacco plants overexpressing Chlamydomonas glutathione peroxidase in chloroplasts or cytosol. Plant J. 2004;37(1):21-33.

[116] Smirnoff N, Wheeler GL. Ascorbic acid in plants: biosynthesis and function. Crit. Rev. Biochem. Mol. Biol. 2000;35(4):291-314.

[117] Xiang C, Werner BL, Christensen EM, Oliver DJ. The biological functions of glutathione revisited in arabidopsis transgenic plants with altered glutathione levels. Plant Physiol. 2001;126(2):564-74.

[118] Meyer AJ. The integration of glutathione homeostasis and redox signaling. J. Plant Physiol. 2008;165(13):1390-403. 
[119] Ashraf M, Foolad MR. Roles of glycine betaine and proline in improving plant abiotic stress resistance. Environmental and Experimental Botany. 2007;59(2):206-16.

[120] Tateishi Y, Nakagawa T, Esaka M. Osmotolerance and growth stimulation of transgenic tobacco cells accumulating free proline by silencing proline dehydrogenase expression with double-stranded RNA interference technique. Physiologia Plantarum. 2005;125(2):224-34.

[121] Simon-Sarkadi L, Kocsy G, Várhegyi Á, Galiba G, De Ronde J. Stress-induced changes in the free amino acid composition in transgenic soybean plants having increased proline content. Biologia Plantarum. 2006;50(4):793-6.

[122] Kamal-Eldin A, Appelqvist LA. The chemistry and antioxidant properties of tocopherols and tocotrienols. Lipids. 1996;31(7):671-701.

[123] Munné-Bosch S, Alegre L. Die and let live: leaf senescence contributes to plant survival under drought stress. Functional Plant Biol. 2004;31(3):203-16.

[124] Gang W, Zhen-Kuan W, Yong-Xiang W, Li-Ye C, Hong-Bo S. The mutual responses of higher plants to environment: physiological and microbiological aspects. Colloids Surf B Biointerfaces. 2007;59(2):113-9.

[125] Filkowski J, Kovalchuk O, Kovalchuk I. Genome stability of vtc1, tt4, and tt5 Arabidopsis thaliana mutants impaired in protection against oxidative stress. Plant J. 2004;38(1):60-9.

[126] Winkel-Shirley B. Biosynthesis of flavonoids and effects of stress. Curr. Opin. Plant Biol. 2002;5(3):218-23.

[127] Apel K, Hirt H. REACTIVE OXYGEN SPECIES: Metabolism, Oxidative Stress, and Signal Transduction. Annual Review of Plant Biology. 2004;55(1):373-99.

[128] Dat JF, Pellinen R, Beeckman T, Van De Cotte B, Langebartels C, Kangasjärvi J, et al. Changes in hydrogen peroxide homeostasis trigger an active cell death process in tobacco. Plant J. 2003;33(4):621-32.

[129] Laloi C, Stachowiak M, Pers-Kamczyc E, Warzych E, Murgia I, Apel K. Cross-talk between singlet oxygen- and hydrogen peroxide-dependent signaling of stress responses in Arabidopsis thaliana. Proc. Natl. Acad. Sci. U.S.A. 2007;104(2):672-7.

[130] Karpinski S, Reynolds H, Karpinska B, Wingsle G, Creissen G, Mullineaux P. Systemic Signaling and Acclimation in Response to Excess Excitation Energy in Arabidopsis. Science. 1999;284(5414):654-7.

[131] Szechyńska-Hebda M, Kruk J, Górecka M, Karpińska B, Karpiński S. Evidence for Light Wavelength-Specific Photoelectrophysiological Signaling and Memory of Excess Light Episodes in Arabidopsis. Plant Cell. 2010;22(7):2201-18.

[132] Jabs T, Dietrich RA, Dangl JL. Initiation of Runaway Cell Death in an Arabidopsis Mutant by Extracellular Superoxide. Science. 1996;273(5283):1853-6. 
[133] Mach JM, Castillo AR, Hoogstraten R, Greenberg JT. The Arabidopsis-accelerated cell death gene ACD2 encodes red chlorophyll catabolite reductase and suppresses the spread of disease symptoms. PNAS. 2001;98(2):771-6.

[134] Gray J, Janick-Buckner D, Buckner B, Close PS, Johal GS. Light-dependent death of maize 1ls1 cells is mediated by mature chloroplasts. Plant Physiol. 2002;130(4):1894907.

[135] Külheim C, Ågren J, Jansson S. Rapid Regulation of Light Harvesting and Plant Fitness in the Field. Science. 2002;297(5578):91-3.

[136] Allen JF. Botany. State transitions--a question of balance. Science.2003;299(5612): 1530-2.

[137] Snyders S, Kohorn BD. Disruption of thylakoid-associated kinase 1 leads to alteration of light harvesting in Arabidopsis. J. Biol. Chem. 2001;276(34):32169-76.

[138] Murchie EH, Horton P. Contrasting patterns of photosynthetic acclimation to the light environment are dependent on the differential expression of the responses to altered irradiance and spectral quality. Plant, Cell \& Environment. 1998;21(2):139-48.

[139] Dietzel L, Pfannschmidt T. Photosynthetic acclimation to light gradients in plant stands comes out of shade. Plant Signal Behav. 2008;3(12):1116-8.

[140] Mullineaux P, Ball L, Escobar C, Karpinska B, Creissen G, Karpinski S. Are diverse signalling pathways integrated in the regulation of arabidopsis antioxidant defence gene expression in response to excess excitation energy? Philos. Trans. R. Soc. Lond., B, Biol. Sci. 2000;355(1402):1531-40.

[141] Bailey S, Walters RG, Jansson S, Horton P. Acclimation of Arabidopsis thaliana to the light environment: the existence of separate low light and high light responses. Planta. 2001;213(5):794-801.

[142] Ballottari M, Dall'Osto L, Morosinotto T, Bassi R. Contrasting behavior of higher plant photosystem I and II antenna systems during acclimation. J. Biol. Chem. 2007;282(12):8947-58.

[143] Mishra Y, Johansson Jankanpaa H, Kiss AZ, Funk C, Schroder WP, Jansson S. Arabidopsis plants grown in the field and climate chambers significantly differ in leaf morphology and photosystem components. BMC Plant Biology. 2012;12(1):6.

[144] Karpinski S, Escobar C, Karpinska B, Creissen G, Mullineaux PM. Photosynthetic electron transport regulates the expression of cytosolic ascorbate peroxidase genes in Arabidopsis during excess light stress. Plant Cell. 1997;9(4):627-40.

[145] Pfannschmidt T, Nilsson A, Allen JF. Photosynthetic control of chloroplast gene expression. Nature. 1999;397(6720):625-8.

[146] Fryer MJ, Ball L, Oxborough K, Karpinski S, Mullineaux PM, Baker NR. Control of Ascorbate Peroxidase 2 expression by hydrogen peroxide and leaf water status dur- 
ing excess light stress reveals a functional organisation of Arabidopsis leaves. Plant J. 2003;33(4):691-705.

[147] Ball L, Accotto G-P, Bechtold U, Creissen G, Funck D, Jimenez A, et al. Evidence for a direct link between glutathione biosynthesis and stress defense gene expression in Arabidopsis. Plant Cell. 2004;16(9):2448-62.

[148] Külheim C, Ågren J, Jansson S. Rapid Regulation of Light Harvesting and Plant Fitness in the Field. Science. 2002;297(5578):91-3.

[149] Mullineaux P, Karpinski S. Signal transduction in response to excess light: getting out of the chloroplast. Curr. Opin. Plant Biol. 2002;5(1):43-8.

[150] Tlalka, Runquist, Fricker. Light perception and the role of the xanthophyll cycle in blue-light-dependent chloroplast movements in lemna trisulca L. Plant J. 1999;20(4): 447-59.

[151] Wingler A, Lea PJ, Quick WP, Leegood RC. Photorespiration: metabolic pathways and their role in stress protection. Philos Trans R Soc Lond B Biol Sci. 2000;355(1402): 1517-29.

[152] Demmig-Adams B, Adams WW 3rd. Photoprotection in an ecological context: the remarkable complexity of thermal energy dissipation. New Phytol. 2006;172(1):11-21.

[153] Li X-P, Muller-Moule P, Gilmore AM, Niyogi KK. PsbS-dependent enhancement of feedback de-excitation protects photosystem II from photoinhibition. Proc. Natl. Acad. Sci. U.S.A. 2002;99(23):15222-7.

[154] Seo S, Okamoto M, Iwai T, Iwano M, Fukui K, Isogai A, et al. Reduced levels of chloroplast FtsH protein in tobacco mosaic virus-infected tobacco leaves accelerate the hypersensitive reaction. Plant Cell. 2000;12(6):917-32.

[155] Slesak I, Karpinska B, Surówka E, Miszalski Z, Karpinski S. Redox changes in the chloroplast and hydrogen peroxide are essential for regulation of C(3)-CAM transition and photooxidative stress responses in the facultative CAM plant Mesembryanthemum crystallinum L. Plant Cell Physiol. 2003;44(6):573-81.

[156] Rossel JB, Wilson PB, Hussain D, Woo NS, Gordon MJ, Mewett OP, et al. Systemic and intracellular responses to photooxidative stress in Arabidopsis. Plant Cell. 2007;19(12):4091-110.

[157] Karpinski S, Escobar C, Karpinska B, Creissen G, Mullineaux PM. Photosynthetic electron transport regulates the expression of cytosolic ascorbate peroxidase genes in Arabidopsis during excess light stress. Plant Cell. 1997;9(4):627-40.

[158] Zhang C, Liu J, Zhang Y, Cai X, Gong P, Zhang J, et al. Overexpression of SIGMEs leads to ascorbate accumulation with enhanced oxidative stress, cold, and salt tolerance in tomato. Plant Cell Rep. 2011;30(3):389-98. 
[159] Wang Z, Xiao Y, Chen W, Tang K, Zhang L. Increased vitamin C content accompanied by an enhanced recycling pathway confers oxidative stress tolerance in Arabidopsis. J Integr Plant Biol. 2010;52(4):400-9.

[160] Eltayeb AE, Yamamoto S, Habora MEE, Matsukubo Y, Aono M, Tsujimoto H, et al. Greater protection against oxidative damages imposed by various environmental stresses in transgenic potato with higher level of reduced glutathione. Breeding Science. 2010;60(2):101-9.

[161] Gupta AS, Heinen JL, Holaday AS, Burke JJ, Allen RD. Increased resistance to oxidative stress in transgenic plants that overexpress chloroplastic $\mathrm{Cu} / \mathrm{Zn}$ superoxide dismutase. Proc Natl Acad Sci U S A. 1993;90(4):1629-33.

[162] Yabuta Y, Motoki T, Yoshimura K, Takeda T, Ishikawa T, Shigeoka S. Thylakoid membrane-bound ascorbate peroxidase is a limiting factor of antioxidative systems under photo-oxidative stress. Plant J. 2002;32(6):915-25.

[163] Li F, Wu Q-Y, Sun Y-L, Wang L-Y, Yang X-H, Meng Q-W. Overexpression of chloroplastic monodehydroascorbate reductase enhanced tolerance to temperature and methyl viologen-mediated oxidative stresses. Physiol Plant. 2010;139(4):421-34.

[164] Tang L, Kwon S-Y, Kim S-H, Kim J-S, Choi JS, Cho KY, et al. Enhanced tolerance of transgenic potato plants expressing both superoxide dismutase and ascorbate peroxidase in chloroplasts against oxidative stress and high temperature. Plant Cell Rep. 2006;25(12):1380-6.

[165] Britt. Molecular genetics of DNA repair in higher plants. Trends Plant Sci. 1999;4(1): $20-5$.

[166] Molinier J, Oakeley EJ, Niederhauser O, Kovalchuk I, Hohn B. Dynamic response of plant genome to ultraviolet radiation and other genotoxic stresses. Mutation Research/Fundamental and Molecular Mechanisms of Mutagenesis. 2005;571(1-2):23547.

[167] Kunz BA, Cahill DM, Mohr PG, Osmond MJ, Vonarx EJ. Plant Responses to UV Radiation and Links to Pathogen Resistance. A Survey of Cell Biology. Academic Press; 2006. p. 1-40.

[168] Danon A, Gallois P. UV-C radiation induces apoptotic-like changes in Arabidopsis thaliana. FEBS Lett. 1998;437(1-2):131-6.

[169] Sinha RP, Häder DP. UV-induced DNA damage and repair: a review. Photochem. Photobiol. Sci. 2002;1(4):225-36.

[170] Kulms D, Schwarz T. Molecular mechanisms of UV-induced apoptosis. Photodermatol Photoimmunol Photomed. 2000;16(5):195-201.

[171] Babu TS, Akhtar TA, Lampi MA, Tripuranthakam S, Dixon DG, Greenberg BM. Similar Stress Responses are Elicited by Copper and Ultraviolet Radiation in the Aquatic 
Plant Lemna gibba: Implication of Reactive Oxygen Species as Common Signals. Plant Cell Physiol. 2003;44(12):1320-9.

[172] Zhang L, Xu Q, Xing D, Gao C, Xiong H. Real-time detection of caspase-3-like protease activation in vivo using fluorescence resonance energy transfer during plant programmed cell death induced by ultraviolet $C$ overexposure. Plant Physiol. 2009;150(4):1773-83.

[173] Gao C, Xing D, Li L, Zhang L. Implication of reactive oxygen species and mitochondrial dysfunction in the early stages of plant programmed cell death induced by ultraviolet-C overexposure. Planta. 2008;227(4):755-67.

[174] Gao Q, Zhang L. Ultraviolet-B-induced oxidative stress and antioxidant defense system responses in ascorbate-deficient vtc1 mutants of Arabidopsis thaliana. J. Plant Physiol. 2008;165(2):138-48.

[175] Molinier J, Oakeley EJ, Niederhauser O, Kovalchuk I, Hohn B. Dynamic response of plant genome to ultraviolet radiation and other genotoxic stresses. Mutat. Res. 2005;571(1-2):235-47.

[176] He R, Drury GE, Rotari VI, Gordon A, Willer M, Farzaneh T, et al. Metacaspase-8 modulates programmed cell death induced by ultraviolet light and $\mathrm{H} 2 \mathrm{O} 2$ in Arabidopsis. J. Biol. Chem. 2008;283(2):774-83.

[177] Harb A, Krishnan A, Ambavaram MMR, Pereira A. Molecular and physiological analysis of drought stress in Arabidopsis reveals early responses leading to acclimation in plant growth. Plant Physiol. 2010;154(3):1254-71.

[178] Yoshiba Y, Kiyosue T, Nakashima K, Yamaguchi-Shinozaki K, Shinozaki K. Regulation of Levels of Proline as an Osmolyte in Plants under Water Stress. Plant Cell Physiol. 1997;38(10):1095-102.

[179] Verslues PE, Sharma S. Proline Metabolism and Its Implications for Plant-Environment Interaction. Arabidopsis Book. 2010

[180] Ramanjulu S, Bartels D. Drought- and desiccation-induced modulation of gene expression in plants. Plant Cell Environ. 2002;25(2):141-51.

[181] Aguirrezabal L, Bouchier-Combaud S, Radziejwoski A, Dauzat M, Cookson SJ, Granier C. Plasticity to soil water deficit in Arabidopsis thaliana: dissection of leaf development into underlying growth dynamic and cellular variables reveals invisible phenotypes. Plant Cell Environ. 2006;29(12):2216-27.

[182] Cosgrove DJ. Growth of the plant cell wall. Nat. Rev. Mol. Cell Biol. 2005;6(11):85061.

[183] Skirycz A, De Bodt S, Obata T, De Clercq I, Claeys H, De Rycke R, et al. Developmental stage specificity and the role of mitochondrial metabolism in the response of Arabidopsis leaves to prolonged mild osmotic stress. Plant Physiol. 2010;152(1):226-44. 
[184] Noctor G, Veljovic-Jovanovic S, Driscoll S, Novitskaya L, Foyer CH. Drought and Oxidative Load in the Leaves of C3 Plants: a Predominant Role for Photorespiration? Ann Bot. 2002;89(7):841-50.

[185] Pei ZM, Murata Y, Benning G, Thomine S, Klüsener B, Allen GJ, et al. Calcium channels activated by hydrogen peroxide mediate abscisic acid signalling in guard cells. Nature. 2000;406(6797):731-4.

[186] Dat J, Vandenabeele S, Vranová E, Van Montagu M, Inzé D, Van Breusegem F. Dual action of the active oxygen species during plant stress responses. Cell. Mol. Life Sci. 2000;57(5):779-95.

[187] Cruz de Carvalho MH. Drought stress and reactive oxygen species. Plant Signal Behav. 2008;3(3):156-65.

[188] Duan Y, Zhang W, Li B, Wang Y, Li K, Sodmergen, et al. An endoplasmic reticulum response pathway mediates programmed cell death of root tip induced by water stress in Arabidopsis. New Phytol. 2010;186(3):681-95.

[189] Bartels D, Sunkar R. Drought and Salt Tolerance in Plants. Critical Reviews in Plant Sciences. 2005

[190] Fujita Y, Fujita M, Shinozaki K, Yamaguchi-Shinozaki K. ABA-mediated transcriptional regulation in response to osmotic stress in plants. J. Plant Res. 2011;124(4):50925.

[191] Rushton DL, Tripathi P, Rabara RC, Lin J, Ringler P, Boken AK, et al. WRKY transcription factors: key components in abscisic acid signalling. Plant Biotechnol. J. 2012;10(1):2-11.

[192] Lee S, Park C-M. Regulation of reactive oxygen species generation under drought conditions in Arabidopsis. Plant signaling \& behavior. 2012

[193] Johansson I, Karlsson M, Johanson U, Larsson C, Kjellbom P. The role of aquaporins in cellular and whole plant water balance. Biochim. Biophys. Acta. 2000;1465(1-2): 324-42.

[194] Skirycz A, Inzé D. More from less: plant growth under limited water. Curr. Opin. Biotechnol. 2010;21(2):197-203.

[195] Pinheiro C, Chaves MM. Photosynthesis and drought: can we make metabolic connections from available data? J. Exp. Bot. 2011;62(3):869-82.

[196] Wasilewska A, Vlad F, Sirichandra C, Redko Y, Jammes F, Valon C, et al. An update on abscisic acid signaling in plants and more. Mol Plant. 2008;1(2):198-217.

[197] Zhao Z, Stanley BA, Zhang W, Assmann SM. ABA-regulated G protein signaling in Arabidopsis guard cells: a proteomic perspective. J. Proteome Res. 2010;9(4):1637-47.

[198] Li M, Hong Y, Wang X. Phospholipase D- and phosphatidic acid-mediated signaling in plants. Biochim. Biophys. Acta. 2009;1791(9):927-35. 
[199] Xiong L, Schumaker KS, Zhu J-K. Cell signaling during cold, drought, and salt stress. Plant Cell. 2002;14 Suppl:S165-183.

[200] Zhang Y, Turner JG. Wound-Induced Endogenous Jasmonates Stunt Plant Growth by Inhibiting Mitosis. PLoS ONE. 2008;3(11):e3699.

[201] Mishra NS, Tuteja R, Tuteja N. Signaling through MAP kinase networks in plants. Arch. Biochem. Biophys. 2006;452(1):55-68.

[202] Urao T, Yakubov B, Satoh R, Yamaguchi-Shinozaki K, Seki M, Hirayama T, et al. A transmembrane hybrid-type histidine kinase in Arabidopsis functions as an osmosensor. Plant Cell. 1999;11(9):1743-54.

[203] Bhatnagar-Mathur P, Vadez V, Sharma KK. Transgenic approaches for abiotic stress tolerance in plants: retrospect and prospects. Plant Cell Rep. 2008;27(3):411-24.

[204] Xu D, Duan X, Wang B, Hong B, Ho T, Wu R. Expression of a Late Embryogenesis Abundant Protein Gene, HVA1, from Barley Confers Tolerance to Water Deficit and Salt Stress in Transgenic Rice. Plant Physiol. 1996;110(1):249-57.

[205] Sivamani, Bahieldin1, Wraith, Al-Niemi, Dyer, Ho, et al. Improved biomass productivity and water use efficiency under water deficit conditions in transgenic wheat constitutively expressing the barley HVA1 gene. Plant Sci. 2000;155(1):1-9.

[206] Liu F-X, Tan Z-B, Zhu J-Q, Deng X-J. [Arabidopsis CBF1 in plant tolerance to low temperature and drought stresses]. Yi Chuan. 2004;26(3):394-8.

[207] Nakashima K, Takasaki H, Mizoi J, Shinozaki K, Yamaguchi-Shinozaki K. NAC transcription factors in plant abiotic stress responses. Biochim. Biophys. Acta. 2012;1819(2):97-103. 